\title{
Afferent Influences on Brain Stem Auditory Nuclei of the Chicken: Presynaptic Action Potentials Regulate Protein Synthesis in Nucleus Magnocellularis Neurons
}

\author{
Donald E. Born and Edwin W Rubel \\ Departments of Otolaryngology and Physiology, and Neuroscience Program, University of Virginia School of Medicine, \\ Charlottesville, Virginia 22908
}

Studies of the avian auditory sytem indicate that neurons in nucleus magnocellularis (NM) and nucleus laminaris of young animals are dramatically altered by changes in the auditory receptor. We examined the role of presynaptic activity on these transneuronal regulatory events. TTX was used to block action potentials in the auditory nerve. TTX injections into the perilymph reliably blocked all neuronal activity in the cochlear nerve and NM. Far-field recordings of sound-evoked potentials revealed that responses returned within 6-12 hr after a single TTX injection. Changes in protein synthesis by NM neurons were measured by determining the incorporation of ${ }^{3} \mathrm{H}$-leucine using autoradiography. NM neurons on the side of the brain ipsilateral to the TTX injection were compared to normally active cells on the other side of the same tissue section.

Grain counts over individual neurons revealed that a single injection of TTX produced a $\mathbf{4 0} \%$ decrease in grain density in ipsilateral NM neurons within $1.5 \mathrm{hr}$ after the TTX injection. However, by $24 \mathrm{hr}$ after a single TTX injection, grain densities were not different on the 2 sides of the brain. Continuous activity blockade for $6 \mathrm{hr}$ caused the cessation of amino acid incorporation in a portion of NM neurons and a 15-20\% decrease in the remaining neurons. These changes in amino acid incorporation are comparable to those following complete removal of the cochlea (Steward and Rubel, 1985). We also examined NM for neuron loss and soma shrinkage after blocking eighth nerve action potentials. TTX injected every $12 \mathrm{hr}$ for $48 \mathrm{hr}$ caused a $20 \%$ neuron loss and an $8 \%$ shrinkage of the remaining neurons. Similar reductions were found following cochlea removal (Born and Rubel, 1985). It is concluded that neuronal activity plays a major role in the maintenance of normal NM neurons. Furthermore, these results

\footnotetext{
Received Apr. 7, 1987; revised Aug. 17, 1987; accepted Aug. 26, 1987.

This work was supported by NIH Grants NS 15395 and MSTP GM 07267, the Pratt Fund at University of Virginia, and the Lions of Virginia. The authors wish to thank Steve Donaldson and Pat Brill for developing computer programs for data collection, Doris Hannum and Pat Palmer for technical assistance, Dr. Mike Merickle and Charles Carman for help with the computer-aided serial reconstructions, Sharon Davis and Patti Peterson for secretarial assistance, and Drs. Oswald Steward, Michael Stryker, Rebecca Code, Thomas Pasic, Dianne Durham, and Dan Sanes for their comments on earlier versions of this manuscript. Knowles Electronics generously provided the microphones used for probe tube calibrations. Portions of this research were submitted by D.E.B. in partial fulfillment of the requirements for the degree of Doctor of Philosophy at the University of Virginia.

Correspondence should be addressed to E. W Rubel at his present address: Department of Otolaryngology, RL-30, University of Washington School of Medicine, Seattle, WA 98195.

Copyright (C) 1988 Society for Neuroscience $0270-6474 / 88 / 030901-19 \$ 02.00 / 0$
}

suggest that transneuronal morphological changes seen in neurons following deafferentation or alterations of sensory experience are a result of changes in the level of presynaptic activity.

Synaptic connections between neurons and their targets have a variety of functions. They provide the mechanism for rapid transfer of information, which occurs within milliseconds, and they are involved in the storage of information, which can last from minutes to years. In addition, over an intermediate time frame, synaptic connections are involved in regulating the structure, metabolism, and even the survival of their postsynaptic target (Harris, 1974). The relationship between these latter functions is not well characterized in the CNS and is the topic of the present study.

Removing synaptic inputs by cutting afferent axons leads to altered physiology, morphology, metabolism, and sometimes loss of the denervated targets, be they muscles, glands, or other neurons (Guth, 1968; Cowan, 1970; Globus, 1975). Alternatively, innervation of targets by nerves with properties different from those of the normal afferent can lead to functional and biochemical modifications in the postsynaptic target (Buller et al., 1960; Streter et al., 1975; reviewed in Close, 1969). While these findings suggest that synaptic inputs play a crucial role in shaping and maintaining target structures, they do not indicate what signals underlie these regulatory properties.

Methods used to investigate the regulation of muscles by motor nerves provide a useful approach to the examination of the processes that underlie synaptic regulation of postsynaptic neurons. The response of skeletal muscle to denervation (removing the presynaptic element by cutting the motor nerve) led early investigators to suggest the importance of synaptic inputs for the maintenance of muscle function (Tower, 1937; Guth, 1968). To investigate what aspect(s) of the "presynaptic" input might be responsible for the changes following denervation, specific processes (such as action potentials, axonal transport, and transmitter release) have been selectively manipulated (reviewed in Harris, 1980; McArdle, 1983). The changes that normally follow denervation provide a standard against which to measure the effect of individual experimental manipulations. Selectively eliminating action potentials in the presynaptic neurons by applying TTX (Hille, 1968; Rogart, 1981) causes reductions in resting membrane potential and increased sensitivity to acetylcholine similar to those produced by denervation (Pestronk et al., 1976; Lavoie et al., 1977). Similarly, the use of axonal transport blockers to eliminate substances that reach the terminals 
Table 1. Groups of animals used in the physiological and histological studies ${ }^{a}$

\begin{tabular}{|c|c|c|c|c|c|}
\hline \multicolumn{3}{|l|}{ Physiological } & \multicolumn{3}{|l|}{ Histological } \\
\hline Technique & Condition $^{b}$ & $\begin{array}{l}\text { Duration } \\
\text { (no. of animals) }\end{array}$ & Technique & Injection ${ }^{c}$ & Survival \\
\hline \multirow[t]{3}{*}{ Microelectrode } & Acute TTX & $1,4,12,18,24 \mathrm{hr}$ ( 1 ea. $)$ & ${ }^{3} \mathrm{H}$-leucine incorp. & $\begin{array}{l}1 \times \mathrm{TTX} \\
1 \times \text { con }\end{array}$ & $\begin{array}{l}1,6,12,24 \mathrm{hr}(6-7 \text { ea. }) \\
1,6,12,24 \mathrm{hr}(1-2 \text { ea. })\end{array}$ \\
\hline & Acute Con & $1,4 \mathrm{hr}$ ( 2 ea.) & & $\begin{array}{l}3 \times \text { TTX } \\
3 \times \operatorname{con}\end{array}$ & $\begin{array}{l}6 \mathrm{hr}(6) \\
6 \mathrm{hr}(2)\end{array}$ \\
\hline & Recovery & $14 d(5)$ & & $\begin{array}{l}2 \times \text { TTX } \\
4 \times \text { TTX }\end{array}$ & 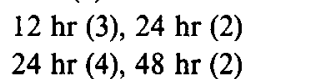 \\
\hline $\begin{array}{l}\text { Microelectrode } \\
\text { and far-field }\end{array}$ & Acute TTX & $1 \mathrm{hr}(5)$ & ${ }^{3} \mathrm{H}$-leucine avail. & $\begin{array}{l}1 \times \text { TTX } \\
3 \times \text { TTX }\end{array}$ & $\begin{array}{l}1 \mathrm{hr}(1) \\
6 \mathrm{hr}(1)\end{array}$ \\
\hline \multirow[t]{3}{*}{ Far-field } & Acute TTX & $1 \mathrm{hr}(10)$ & $\begin{array}{l}\text { Neuron no. } \\
\text { Soma area }\end{array}$ & $4 \times \mathrm{TTX}$ & $48 \mathrm{hr}(6)$ \\
\hline & Acute Con & $1,4 \mathrm{hr}(2 \mathrm{ea})$. & & $3 \times$ TTX \& recovery & $7 d(5)$ \\
\hline & Recovery & $7 \mathrm{~d}(6)$ & Degeneration & $3 \times$ TTX \& recovery & $1-4$ d (1 ea.) \\
\hline
\end{tabular}

\footnotetext{
animals that had the cochlea removed contralateral to the TTX injection are not included. TTX, tetrodotoxin injected. Con, control solution injected.
}

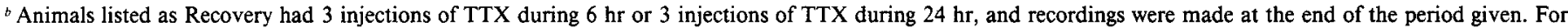
Acute the recordings were made at the time of the injection.

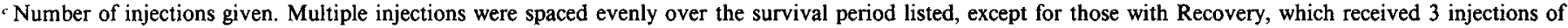
TTX during $6 \mathrm{hr}$ at the beginning of the survival period.

via axonal transport indicates a possible role for chemical processes independent of synaptic transmission (Albuquerque et al., 1972; Warnick et al., 1977).

The structural and functional integrity of neurons in the CNS also depends on the presence of normally functioning afferents. Numerous experiments in which afferents to CNS neurons are disrupted clearly demonstrate the importance of presynaptic inputs (Powell and Erulkar, 1962; Cowan, 1970; Pinching and Powell, 1971; Guillery, 1974; Globus, 1975). Recently, investigators have used TTX to block action potentials from the eye in order to evaluate the effects of eliminating presynaptic activity on the formation of visual system connections during development and regeneration (Reh and Constantine-Paton, 1985; Chapman et al., 1986; Stryker and Harris, 1986). However, elucidation of the specific presynaptic processes that underlie the metabolic and structural integrity of target neurons in the CNS has been hampered by several problems. These include the complexity of the interconnections among neurons, insufficient information on the time course and degree of the presynaptic degeneration, and the lack of easily quantifiable responses in postsynaptic neurons.

Brain-stem auditory neurons in the chick have provided a useful preparation in which to study the influence of presynaptic inputs on postsynaptic neurons in the CNS (Rubel et al., 1984). Second-order neurons in nucleus magnocellularis (NM) receive their major excitatory input from the cochlca (basilar papilla) via the eighth nerve (Ramon y Cajal, 1909; Boord and Rasmussen, 1963; Parks and Rubel, 1978; Sachs and Sinnott, 1978; Born and Rubel, 1984). If the otocyst is removed early in development, approximately $30 \%$ of ipsilateral NM neurons die (Levi-Montalcini, 1949; Parks, 1979). Cochlea removal in hatchling chickens also produces changes in NM neurons. These include loss of $25-30 \%$ of NM neurons, a $15 \%$ decrease in soma cross-sectional area of the remaining neurons, altered succinate dehydrogenase levels, and alterations in cytoskeletal elements (Born and Rubel, 1985; Durham and Rubel, 1985a; Seftel et al., 1986). Autoradiographic investigations indicate that protein synthesis is reduced in NM neurons by $50 \%$ within $0.5 \mathrm{hr}$ after cochlea removal. By $6 \mathrm{hr}$ after cochlea removal, protein synthesis ceases in approximately one-quarter of the neurons (Steward and Rubel, 1985). The numerical correspondence between the proportion of neurons that cease incorporating amino acids and the proportion of neurons that die (which is supported by the finding that no unlabeled neurons are found $4 \mathrm{~d}$ after a single injection of ${ }^{3} \mathrm{H}$-leucine; E. W Rubel and O. Steward, unpublished observations) indicates that changes in amino acid incorporation can be used to predict the fate of NM neurons following cochlea removal. Thus, amino acid incorporation can be used as a rapid indicator of long-term postsynaptic change in NM neurons.

The experiments reported here are based on the hypothesis that elimination of eighth nerve action potentials is responsible for some, or all, of the postsynaptic changes observed following cochlea removal. To test this hypothesis, we blocked activity in the eighth nerve ganglion cells with TTX and compared the response in NM to that following cochlea removal. TTX was injected into the perilymph, which bathes the cochlea and eighth nerve ganglion cells. We observed reductions in amino acid incorporation, neuron number, and soma size that were similar in rate and magnitude to those following cochlea removal.

\section{Materials and Methods}

Subjects

Chickens ( $n=119)$ used in this study were hatched from eggs ( $H$ \& $N$ breed, Truslow Farms, MD) and were raised in communal brooders. All animals had free access to food and water. On the day of surgery, 2-3 weeks after hatching, they were moved to separate brooders without food. The animals were divided among the treatment conditions listed in Table 1.

\section{TTX injections}

Surgical preparations. Chicks were anesthetized with a combination of ketamine $(80 \mathrm{mg} / \mathrm{kg}$, i.m. $)$ and sodium pentobarbital $(25 \mathrm{mg} / \mathrm{kg}$, i.p. $)$ or by incubation of halothane vapors. The subjects were secured in a specially designed head-holder within a double-walled, sound-attenuating room (Industrial Acoustics). The cartilage around the extenal ear was removed bilaterally to permit delivery tubes of a closed sound system to be sealed to the ear canal. 
Injecting TTX directly into the cochlear duct disrupts the integrity of cochlear fluids, which itself can lead to changes in auditory ncrve activity (Tucci et al., 1987). Therefore, we injected the toxin into the perilymph of the vestibular system at the saccule. The right periotic bone posterior and dorsal to the ear canal was opened. A small hole (approximately 1 $\mathrm{mm}$ ) was made in the bony labyrinth at the saccule, exposing the dorsal surface of the saccular duct. This injection site was verified in serial reconstructions of sample cases.

TTX preparation and injection. Lyophilized TTX with citrate (Sigma) was dissolved in distilled water, aliquoted, dried under vacuum, and stored at $5^{\circ} \mathrm{C}$. A fresh working solution of $3 \mathrm{~mm}$ TTX was prepared by adding a solution of $0.9 \% \mathrm{NaCl}$ and $0.1 \%$ Alcian blue (Roboz). Glass microelectrodes were filled with the TTX solution, and the tip was broken to a diameter of $2-3 \mu \mathrm{m}$. The pipette was lowered through the membrane of the exposed right saccule with the aid of a micromanipulator. Twenty to thirty pounds of pressure were applied to the micropipette in brief pulses. The pulse duration and total time of the injection were adjusted to inject an appropriate final volume, which was determined in physiological studies (described below). The volume was determined by making an equivalent injection into mineral oil, measuring the diameter of the drop, and calculating its volume. Following the injection, Gelfoam (Upjohn) was placed over the fistula in the saccule, and the animal quickly recovered. Some of the animals were reanesthetized and received additional TTX injections.

Control injections. Control experiments in which the saccule was exposed and control solutions were injected indicated that the integrity of the auditory periphery is maintained. There were no changes in spontaneous neuronal discharges or in thresholds for multiunit discharges in NM. Control solutions consisted of either vehicle $(0.9 \% \mathrm{NaCl}$ with Alcian blue) or acid-inactivated TTX (TTX dissolved in $\mathrm{HCl}$ then neutralized) in vehicle. Injection procedures were identical to those for animals receiving TTX.

Contralateral cochlea removal. Some of the animals that underwent TTX injection in one ear had their contralateral cochlea removed. The methods for removing the cochlea have been described previously (Born and Rubel, 1985). Briefly, prior to the first TTX injection, the contralateral tympanic membrane was opened, and the columella was removed to allow visualization of the oval window. The cochlea (basilar papilla) was removed using fine forceps. Gelfoam was placed in the oval window opening to control the minimal bleeding associated with this procedure.

\section{Electrophysiological recording}

Electrical activity in NM was monitored during and after TTX injections. Microelectrodes were placed in NM to determine the TTX dose required to block eighth nerve impulse activity and to assess the duration of the block. We also employed a noninvasive recording procedure, using subdermal pin electrodes to record far-field evoked responses to acoustic stimuli. Since we found that a $50 \%$ decrease in evoked potential amplitude was a reliable indicator of complete unilateral eighth nerve action potential blockade, all animals used in the histological studies were monitored for changes in far-field evoked responses at the time of the TTX injection.

\section{Microelectrode recording procedures}

Surgical preparations. Chicks were prepared in the same manner as for TTX injections. Supplementary doses of ketamine $(30 \mathrm{mg} / \mathrm{kg})$ and pentobarbital $(0.5 \mathrm{ml} / \mathrm{kg})$ were given as needed to maintain a consistent level of anesthesia, as indicated by the lack of nociceptive responses. Atropine $(0.01 \mathrm{mg} / \mathrm{kg})$ was injected subcutaneously to reduce tracheal secretions. A tracheostomy was performed and the trachea cannulated to maintain an adequate airway. Small wood screws were inserted into the parietal bone and fixed to the head-holder, using dental acrylic. The skin and bone overlying the cerebellum were removed. In most cases the cerebellum was aspirated to expose the floor of the fourth ventricle, where the cochlear nerve fibers coursc rostromedially over the medulla.

Acoustic stimuli. Pure tone stimuli were used to locate brain-stem auditory structures and to assess the response of NM neurons. Tones were generated using a function generator (Krohn-Hite 5910) and transduced by miniature earphones (Bruel and Kjaer HT0003). The earphones were fixed to sound-delivery tubes that were sealed to each ear canal. Stimulus presentation and intensity were controlled by an electronic switch and digital attenuator under computer control. The sound pressure level at the external auditory meatus was measured using a calibrated probe tube that extended to the tip of the sound-delivery tube and was connected to a microphone (Knowles BL 1830). The intensities of tones from 0.1 to $5 \mathrm{kHz}$ were measured using a narrowband spectrum analyzer (Bruel and Kjaer 2031) at the beginning of each experiment. These measurements provided an on-line calibration of the sound-delivery system for each subject.

Recording procedures. Electrical potentials were recorded through glassinsulated tungsten microelectrodes (1-4 M $\Omega$ impedance). Potentials from the electrode were amplified, filtered to pass $0.4-10 \mathrm{kHz}$, displayed on an oscilloscope, recorded on magnetic tape, and led to a pulse-height discriminator. The output of the discriminator was used for compiling "spike" counts.

Changes in electrical activity in NM were quantified in the following way: The electrode was first lowered into the cerebrospinal fluid above the brain; the activity level recorded here was defined as the electrical noise level. A pulse-height discriminator was set such that the trigger level was above the electrical noise level by an amount equal to half the peak-to-peak amplitude of the electrical noise. The discriminator level remained at this setting throughout the remainder of the experiment. The electrode was then lowered into the medulla, and NM was located by its response to pulsed tones. Spikes were counted in $1 \mathrm{sec}$ bins, and the average of 100 bins was calculated using a PDP 11/23 computer. Spontaneous activity in NM was measured before, during, and after injection of either TTX, acid-inactivated TTX, or vehicle into the perilymph of one ear. (Spontaneous activity is defined here as the level of activity recorded in the sound-attenuating room with sounddelivery tubes in place but with no stimulus.) The multiunit traces and spike rates were analyzed to find a dose of TTX that reduced the activity in the ipsilateral NM to the level of the electrical noise. We also recorded in nuclei adjacent to NM to assess the specificity of the activity changes resulting from TTX injection.

In addition to spontaneous activity, we examined neuronal activity in response to pure tone stimuli. Tone bursts were $1 \mathrm{sec}$ in duration, with 4 msec rise/fall times, and were presented once every 2 sec. Rateintensity functions were generated by presenting tones of increasing intensity at the characteristic frequency $(\mathrm{CF})$ of the neurons.

Histological procedures. At the conclusion of each experiment a small electrolytic lesion was made at the recording site. The chicken was then given an overdose of pentobarbital and transcardially perfused with $10 \%$ buffered formalin. The head was placed in fixative for 1-3 weeks. The brain was then removed, dehydrated, embedded in paraffin, and sectioned at $10 \mu \mathrm{m}$ in the coronal plane. Sections were mounted on glass slides, stained with thionin, and examined to verify the position of the electrode tip.

\section{Far-field evoked potentials}

Recording procedures. Far-field evoked potentials were recorded using 3 subdermal electrodes: two were placed along the midline of the head, anterior and posterior to the external ear canals, and the third, which served as a ground, was placed in the thigh muscle. Initially, far-field evoked potentials were studied while simultaneously recording from a microelectrode located in NM. Responses were amplified, filtered to pass $40-4000 \mathrm{~Hz}$, digitized by an analog-to-digital converter at a ratc of $10 \mathrm{kHz}$, and then averaged over 200 stimulus presentations. Before and after an injection of TTX, a stimulus of constant intensity was presented. The stimulus was a click with an intensity of $80 \mathrm{~dB}$ peak equivalent sound pressure level (SPL) generated from 1 cycle of a $5 \mathrm{kHz}$ sine wave. Changes in evoked potential amplitude were expressed as a percentage of the initial response. Owing to the response of the normal contralateral ear, the far-field evoked potential is not abolished even when TTX eliminates all action potentials in the ipsilateral eighth nerve. The percentage decrease in evoked potential observed with a dose of TTX that eliminated all multiunit activity in the ipsilateral NM was used as a criterion for a successful injection. Animals that failed to show this degree of change in the evoked response were not included in further analyses.

Threshold measurement. Although the injection site was remotc from the cochlea and cochlear ganglion cells, there may have been some nonspecific damage caused by the injection procedure or by the toxin itself. To test for permanent damage to the cochlea or ganglion cells, we tested for hearing loss after the toxin had worn off by measuring evoked potential thresholds at 4 different frequencies. Seven days after a series of 3 TTX injections (spaced at $2 \mathrm{hr}$ intervals), far-field evoked potential thresholds were obtained to stimuli at octave intervals ranging from 500 to $4000 \mathrm{~Hz}$. The pure tone stimuli were presented through sound-delivery tubes as described above. The tones were $20 \mathrm{msec}$ in 
duration, with $2 \mathrm{msec}$ rise/fall times, and were presented at $2 \mathrm{~Hz}$. Subdermal pin electrodes were placed as described above, or pin electrodes were implanted in the left and right cerebellar hemispheres. Threshold was defined as the lowest intensity at which a reliable response could be detected by visual examination of the averaged evoked potential derived from 200 stimulus presentations. Mean thresholds at each frequency were calculated by combining the data across animals.

\section{Amino acid incorporation}

${ }^{3} \mathrm{H}$-Leucine injections. Injection of ${ }^{3} \mathrm{H}$-leucine, survival periods, tissue processing, and autoradiographic techniques were similar to those described by Steward and Rubel (1985). Chickens that were given a single dosc of TTX or control solution were given a single intracardiac injection of ${ }^{3} \mathrm{H}$-leucine $1,6,12$, or $24 \mathrm{hr}$ later. Chickens given multiple TTX injections had a single intracardiac injection of ${ }^{3} \mathrm{H}$-leucine $6-48 \mathrm{hr}$ after the initial TTX injection. Each animal received $0.5 \mathrm{mCi}$ of ${ }^{3} \mathrm{H}$-leucine (40-60 $\mathrm{mCi} / \mathrm{mmol}$ leucine; ICN Radiochemical or New England Nuclear) in $0.5 \mathrm{ml}$ of $0.01 \mathrm{~N} \mathrm{HCl}$ while on its back in a state of tonic immobility. The intracardiac injection was completed rapidly and the chickens did not show behavioral signs of distress when they were maintained on their backs during the procedure.

Tissue preparation. Thirty minutes after the ${ }^{3} \mathrm{H}$-leucine injection, each chicken was deeply anesthetized with pentobarbital, perfused transcardially with $10 \%$ buffered formalin, and the head was placed in the same fixative. After 1 week the brain was dissected from the skull, dehydrated, and embedded in paraffin. Coronal sections were cut at $6 \mu \mathrm{m}$ and a 1 -in-4 scrics was mounted on acid-cleaned slides. The slides were dipped in Kodak NTB2 emulsion (diluted 1:1 with distilled water), using standard autoradiographic techniques (Rogers, 1979). After 2-6 weeks of exposure at $5^{\circ} \mathrm{C}$, the autoradiograms were developed in D19 (Kodak), fixed in Rapidfix (Kodak), and lightly stained through the emulsion with thionin. When radioactive amino acids are injected and the tissue processed in this manner, the extent of autoradiographic labeling is thought to reflect the extent of protein synthesis and the sites at which synthesis occurs (Droz and Leblond, 1963). A 30 min postinjection survival period allowed sufficient time for $95 \%$ of the total incorporation found at any time after a single injection of ${ }^{3} \mathrm{H}$-leucine, but was short enough to minimize transport of labeled proteins from the sites of synthesis (Droz and Leblond, 1963).

Unfixed tissue. Two animals were prepared for an assessment of the availability of the ${ }^{3} \mathrm{H}$-leucine and its uptake by NM neurons. In these cases the brains were prepared for autoradiography without fixation to allow assessment of the relative uptake of ${ }^{3} \mathrm{H}$-leucine in NM after TTX treatment. The animals were injected with TTX, and later injected with ${ }^{3} \mathrm{H}$-leucine, as described above. Thirty minutes later, each animal was deeply anesthetized with sodium pentobarbital and killed by decapitation. The brains were rapidly removed and frozen in heptane cooled with dry ice. Twelve micron coronal sections were cut on a cryostat at $-20^{\circ} \mathrm{C}$. Sections were thaw-mounted onto subbed slides, dried, and exposed to coverslips dipped in NTB2 emulsion (Young and Kuhar, 1979). Autoradiograms prepared in this manner from unperfused tissue should refiect the distribution of both incorporated and unincorporated precursor.

Grain counts. The autoradiograms were analyzed quantitatively by counting silver grains on both sides of the brain over NM somata in which a nucleus was visible. For each animal, the complete posteriorto-anterior extent of both magnocellular nuclei was determined and a section at the midpoint of both nuclei was selected. At this level of the nucleus, this yielded at least 40 neurons on each side of the brain. The cross-sectional area of the soma of each neuron was also determined and grain density (number of grains divided by soma cross-sectional area) was calculated. Comparing grain densities on both sides of the same brain section reduced the possible contribution of variables such as emulsion thickness, section thickness, and posterior-to-anterior location in NM. Any difference in grain density between the 2 sides of the brain could then be attributed to the experimental manipulation.

Two computer-aided methods were used to count silver grains. In the first method, using a Zeiss Videoplan Morphometry System, an image obtained through a $100 \times$ planapochromatic objective (N.A. 1.3) was displayed on a video monitor. The experimenter counted each of the grains lying above individual neurons and outlined the soma for determination of soma cross-sectional area. In the second method, a similar microscope image was digitized (Gould-Deanza system interfaced to a PDP $11 / 70$ computer) and again displayed on a video monitor. The experimenter outlined NM neuron somata, and the number of grains above each outlined neuron was determined by the computer using a thresholding algorithm (Breeden et al., 1986).

We compared the results obtained with the 2 methods by using both counting methods on the same tissue. Grain densities using the 2 methods did not differ by more than $5 \%$. We also assessed the linear range of both grain-counting techniques by performing counts on autoradiograms from plastic standards with specific activities ranging from 3 to $150 \mathrm{nCi} / \mathrm{mg}$ (Amersham). The standards were mounted on slides and exposed to emulsion using the same procedures as for tissue sections. Only autoradiograms for which grain counts were within the linear range were used.

Data analysis. Because NM receives projections only from the ipsilateral cochlea (Boord and Rasmussen, 1963; Parks and Rubel, 1978), the NM neurons contralateral to a TTX injection should have normal levels of protein synthesis and serve as a within-animal control. Mean grain densities for neurons ipsilateral and contralateral to the TTX injection were compared for each animal. We used several techniques to compare the various groups.

Absolute grain densities vary among animals because of such factors as delivery of isotope, perfusion, emulsion, and development. Thus, the raw data cannot be combined across animals. To assess grouped data, the following normalization procedures were used. For each animal, the mean grain density on the side of the brain ipsilateral to the TTX injection was expressed as a percentage of the mean grain density on the contralateral "control" side. The average of these scores was then calculated for each group. In addition, a standard score ( $z$ score) was calculated for the grain density of each neuron on the basis of the mean and standard deviation of grain density on the control side of each brain. Since the number of neurons on each side of the individual tissue sections was similar (40-60), the standard scores could then be combined for each experimental group. A normalized distribution of grain densities was plotted for each group of animals, and a meaningful between-animal estimate of differences in grain density could be computed.

\section{Additional histological procedures}

Neuron counts and soma cross-sectional area measurements in NM provided additional comparisons of neuronal changes following injections of TTX to those following cochlea removal. Neurons were counted in thionin-stained sections from chickens that received injections of TTX every $12 \mathrm{hr}$ for $48 \mathrm{hr}$. The survival period and the quantitative techniques were identical to those used to examine the consequences of cochlea removal (Born and Rubel, 1985). Counts were performed on a 1-in-4 series of $10 \mu \mathrm{m}$ thionin-stained sections. With the aid of a microscope equipped with a $40 \times$ oil-immersion objective (N.A. 1.4) and an eyepiece reticule, each neuron with stained cytoplasm, a clear nucleus, and a nucleolus was counted. No correction factor was employed because of the small diameter of the nucleolus (used in the counting criteria) relative to the section thickness (Konigsmark, 1970). Totals were calculated by multiplying the count by 4 and the neuron loss was calculated from the difference between the 2 sides of the brain expressed as a percentage of the number of neurons on the side contralateral to the TTX injection.

Soma cross-sectional area was measured on both sides of the brain in one section at each of 3 levels of the posterior-to-anterior extent of NM (33, 50, and 66\%). These levels represent zones of neurons that respond to increasing sound frequencies. With the aid of a microscope and a video morphometry system (Zeiss Videoplan), somata that had a stained cytoplasm, a clear nuclear area, and a nucleolus were outlined at their largest profile and the cross-sectional area was calculated. The mean of the individual soma areas on each side of the brain was calculated and the percentage difference in soma area was calculated. The percentage differences from the 3 levels measured were averaged, and a mean percentage change in soma area for each group of animals was calculated by averaging across animals.

In addition to the physiological tests for toxic effects of TTX on the cochlea or eighth nerve, we examined brain stem auditory nuclei for anatomical evidence of axon or terminal degeneration. Five chickens were given 3 injections of TTX during a $6 \mathrm{hr}$ period. Two additional chickens sustained unilateral cochlea removal and served as positive controls (see Parks and Rubel, 1978). After 1-4 d, each animal was given an overdose of Nembutal and was transcardially perfused with $10 \%$ formalin. Brain stems were sectioned on a freezing microtome at $20 \mu \mathrm{m}$ and processed by the first procedure of Fink and Heimer (1967). 

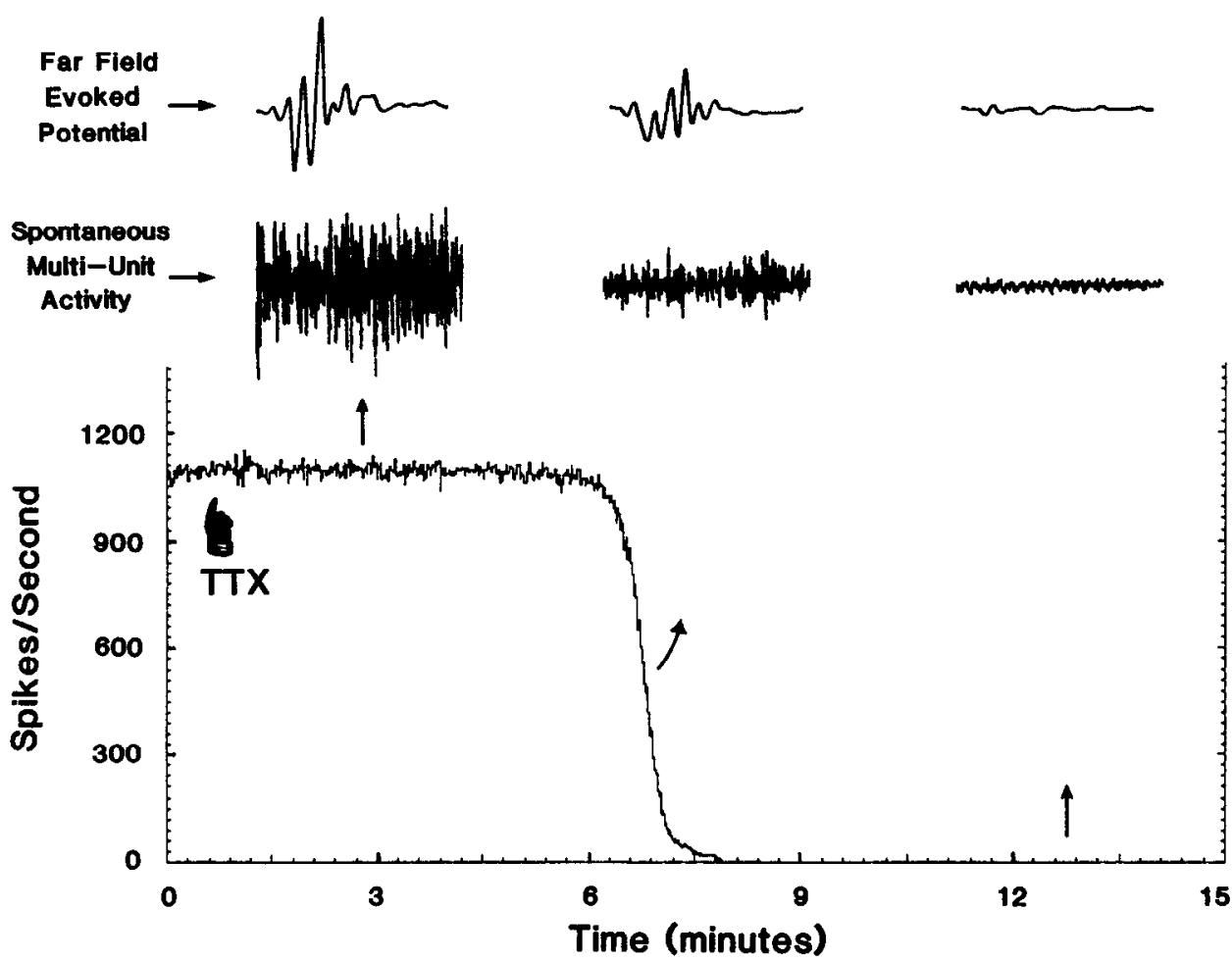

Figure 1. Graph of spike rate in nucleus magnocellularis (NM) as a function of time. Immediately above the graph are samples of the microclectrode output during the periods indicated (arrows). Above the traces from the microelectrode recordings are far-field evoked potential averages recorded from the same animal at the same time, using subdermal electrodes (averages of 200 repetitions). The pointer indicates the time of the TTX injection. In this animal, the contralateral cochlea was removed prior to TTX injection. Approximately 1100 spikes/sec are recorded in NM under these conditions. Six minutes after a $0.1 \mu \mathrm{l}$ injection of a $3 \mathrm{~mm}$ TTX solution (pointer), there is a precipitous drop in the spike rate. Within a minute, no more spikes are recorded. The spontaneous neural potentials are seen to decrease to a level similar to the electrical noise of our recording system. Elimination of the evoked potential is coincident with the decrease in action potentials. The small peaks that are preserved in the evoked potential recording are the cochlear microphonic, which is maintained after TTX injection.

\section{Results}

TTX injections were made in 101 chickens. The animals were used for anatomical studies recovered rapidly from the anesthesia and showed no sign of systemic toxicity. However, most of the animals injected with TTX were unable to hold their heads in an upright position and had difficulty standing. These deficits were probably due to the acute effects of TTX on vestibular organs, and were never seen in the 10 animals injected with saline or acid-inactivated TTX.

The results will be presented in four sections. Electrophysiological observations on the immediate and long-term effects of TTX are presented first, followed by the data from control conditions. The autoradiographic results are described next. Finally, other comparisons with cochlea removal, including neuron counts, soma area measurements, and results from animals that had the cochlea removed contralateral to TTX injection are presented.

\section{Effects of TTX on neuronal activity}

Short-term changes in spontaneous activity. A metal microelectrode placed in NM of an anesthetized hatchling chicken records a high level of spontaneous activity. With the pulse-height discriminator arbitrarily set so that it was $1.5 \times$ the baseline (see Materials and Methods), approximately 1200 spikes/sec are detected while recording in NM. TTX injected into the perilymph has a dramatic effect on this spontaneous activity in the ipsilateral NM. Figure 1 shows the results of a typical injection. The graph shows spike rate as a function of time, as well as representative traces from several time intervals (indicated by the arrows). Five to 10 minutes after injecting $0.1 \mu 1$ of the 3 mM TTX solution into the perilymph, there is a precipitous drop in the number of spikes recorded in NM. Except for the 6 min delay, the decline in spike rate is comparable in rate and magnitude to that following cochlea removal (Born and Rubel, 1984). As shown in the traces above the spike rate graph, the peak-to-peak amplitude of spontaneous neuronal activity shrinks following TTX injection to levels associated with the electrical noise recorded in the cerebrospinal fluid above the brain stem. These results indicate that presynaptic impulse conduction in the eighth nerve has been blocked, and that there are no detectable spontaneous postsynaptic action potentials in NM. Cessation of spontaneous neuronal activity in NM occurred reliably with injections of $0.1 \mu \mathrm{l}$ of $3 \mathrm{mM}$ TTX into the perilymph. Results similar to those shown in Figure 1 were obtained from all 10 animals in which the electrode was verified to have been in NM.

Short-term changes in far-field evoked potentials. Far-field evoked potentials were used as a noninvasive measure of physiological changes following TTX injections. The relationship between changes in spontaneous neuronal activity in NM and in far-field evoked potentials was studied in 5 animals by simultaneously recording with a microelectrode in NM and with subdermal electrodes. The top traces in Figure 1 show far-field evoked potentials recorded in the same animal. In this case, the contralateral cochlea was removed, so that the far-field response represents only the response of the ipsilateral ear. Comparison of the extracellularly recorded spikes and the far-field evoked potential shows that the amplitude of the evoked potential falls in association with the decrease in spontaneous and evoked neuronal discharges. When the contralateral ear is intact, the evoked potential decreased after TTX injection but is not eliminated. The evoked potential amplitude dropped at least $50 \%$ in the 5 animals in which injections of TTX eliminated neuronal activity in NM. In addition, the evoked potential threshold increased by $20-25 \mathrm{~dB}$, which is consistent with what is expected from direct assessment of interaural isolation.

It is possible that the procedures used to record multiunit 


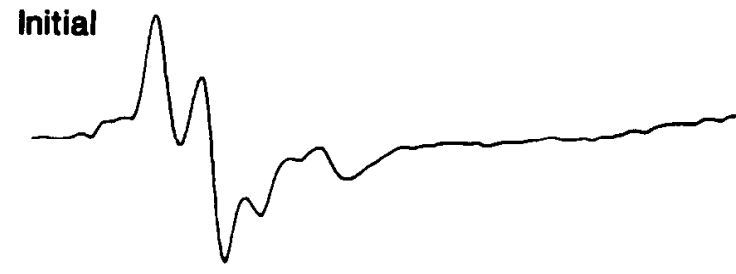

10 Min After TTX Injection

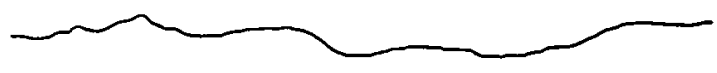

10 Hours After TTX Injection

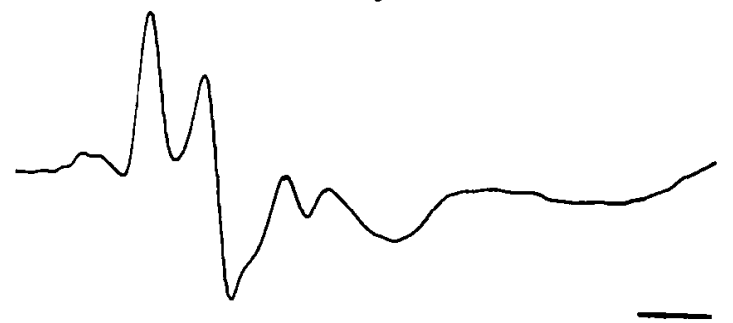

Figure 2. Averaged sound-evoked potentials recorded from subdermal electrodes in a chicken before any experimental manipulation, $10 \mathrm{~min}$ after a single injection of TTX, and $10 \mathrm{hr}$ later. The stimulus in all cases was a click generated from 1 cycle of a $5 \mathrm{kHz}$ sine wave at $80 \mathrm{~dB}$ SPL (peak equivalent), and each trace is the average of 200 repetitions. Within 20 min after injection of TTX, the evoked potential is eliminated. By $10 \mathrm{hr}$ later, the evoked potential has recovered to the premanipulation baseline. Bar, $1 \mathrm{msec}$.

spontaneous activity in NM contribute to the observed change in far-field evoked potentials recorded in the same animal. We examined this potential problem by injecting 10 animals with TTX while recording only evoked potentials using subdermal electrodes. These animals showed the same rapid change in the evoked response as is found during the microelectrode recording experiments. That is, the evoked potential response decreased by at least $50 \%$ and thresholds increased by at least $20 \mathrm{~dB}$ within 10 min of the TTX injection.

Duration of $T T X$ action. Following a single $0.1 \mu \mathrm{l}$ injection of 3 mM TTX, chickens were maintained under anesthesia for $4,12,18$, or $24 \mathrm{hr}$ while microelectrode recordings were made in NM. After the initial precipitous decrease in spontaneous and sound-evoked multiunit activity, there was no recovery of potentials recorded in any of these animals. These results indicated that in continuously anesthetized chickens the effect of TTX lasts at least $24 \mathrm{hr}$.

Although the microelectrode recordings indicated that TTX produced a long-lasting conduction block, there was an important difference between animals prepared for microelectrode recording and those to be used in the histological analyses. Unlike the animals continuously anesthetized for physiological recording, birds in which amino acid incorporation was to be assessed were only briefly anesthetized. To investigate changes in conduction following single TTX injections, we examined far-field evoked potentials in chickens that were anesthetized only for the duration of the TTX injection. Six to $12 \mathrm{hr}$ after a single injection of TTX, the animal was reanesthetized and

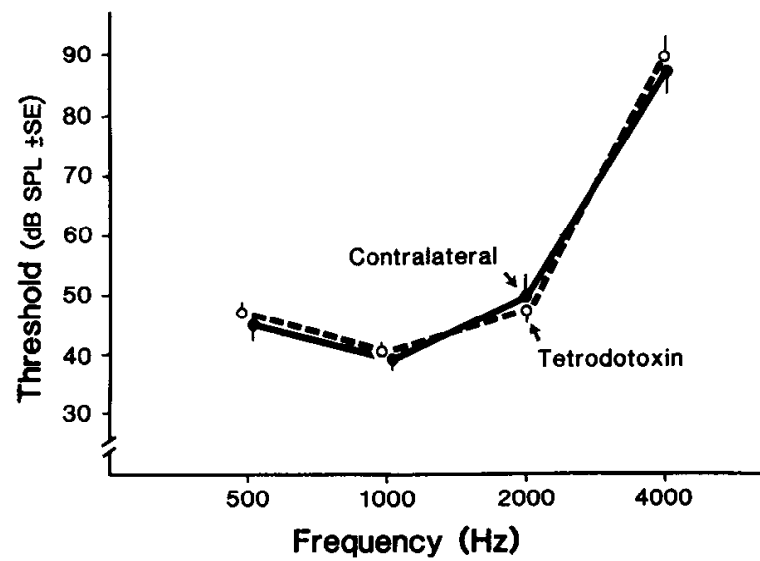

Figure 3. Far-field evoked potential threshold/frequency functions. Recordings were made in 6 animals 1 week after 3 injections of TTX were given at $2 \mathrm{hr}$ intervals. The threshold at each frequency was averaged across animals within the group. The thresholds on the side ipsilateral to the TTX injections are the same as those on the contralateral (normal) side, indicating that the cochlea and ganglion cells are functionally normal at the time of testing.

prepared for recording far-field evoked potentials. To limit the evoked response to the injected ear, the contralateral cochlea was removed. Figure 2 shows the evoked potentials from a representative animal at the time of the initial injection of TTX and $10 \mathrm{hr}$ later. While the evoked potential was eliminated shortly after TTX injection (Fig. 2, top versus middle trace), 10 hr later the evoked potential had returned to nearly normal amplitude (Fig. 2, bottom trace). These results suggested that action potentials in the eighth nerve were no longer completely blocked. A similar result was obtained in all animals subjected to repeated evoked potential analysis. The lack of extracellular spike activity in NM and the presence of a far-field evoked response is probably not due to differences in the recording techniques. Rather, the difference can probably be attributed to the depressive effects of long-term anesthesia on factors such as metabolism, circulation, and general movement (reducing diffusion and inactivation). Thus, far-field evoked potential recordings indicate that in chickens not continuously anesthetized, such as those prepared for the histological analyses discussed below, there was probably a return of sound-elicited and spontaneous activity in NM within $6 \mathrm{hr}$ of a single TTX injection. This conclusion has not been verified by recording unit activity in awake unanesthetized birds; it is based on the correlation between evoked potentials and unit activity established in this study and others (Dubin et al., 1986).

\section{Control procedures}

Tests for nonspecific effects of TTX. Injections of vehicle or acidinactivated TTX in vehicle were used to examine nonspecific effects of the injection procedure, such as volume or $\mathrm{pH}$ changes, and any damage to the auditory system due to opening the saccule. Injections of control solutions never produced a change in neuronal spontaneous activity or sound-evoked multiunit thresholds $(n=4)$. In addition, far-ficld cvokcd potential thresholds remained unaffected after an injection of control solutions $(n=4)$.

It is also possible that the effects of TTX spread beyond the cochlea and ganglion cells and directly blocked activity in NM. We examined this possibility by recording in adjacent brain 


\section{Spontaneous}

\section{Contralateral to Injection}

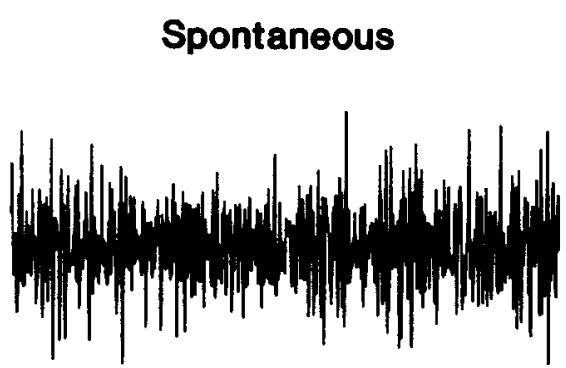

1196 Spikes/Second
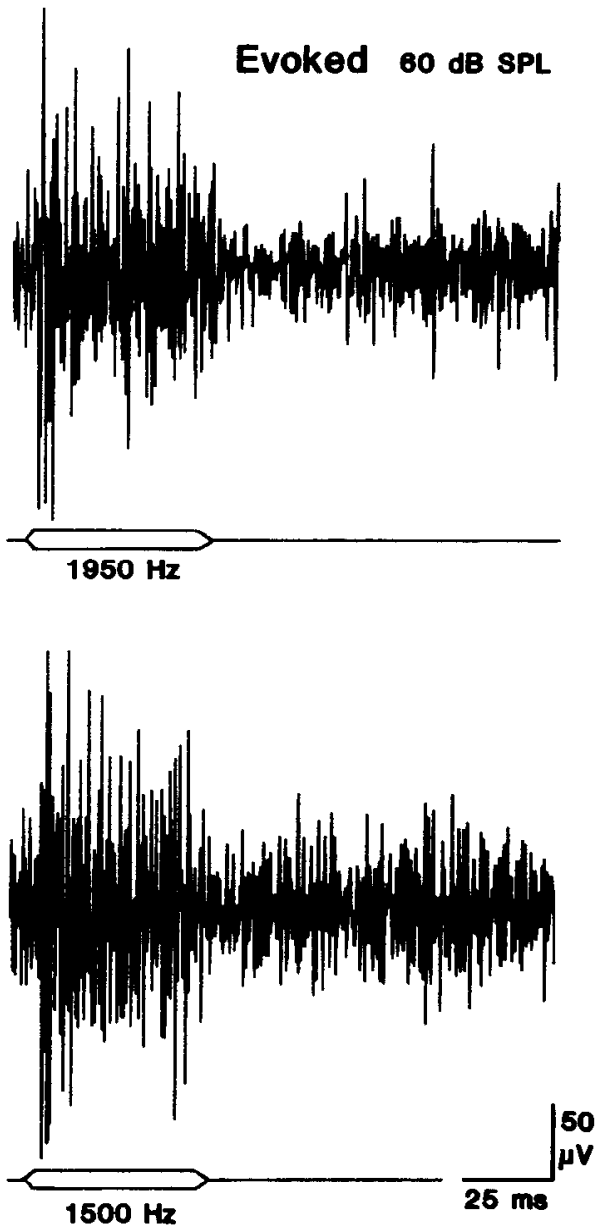

Figure 4. Spontaneous and evoked neuronal activity recorded in NM ipsilateral and contralateral to 3 injections of TTX spaced at 2 hr intervals and given 2 weeks prior to the recording. On both sides of the brain, we recorded levels of neuronal activity that were similar to one another and to those of normal animals in both amplitude and spike rate (indicated below each trace). The response to a pure tone stimulus presented at the area's characteristic frequency (indicated) is shown at the right and was also not noticeably altered by the exposure to TTX.

stem structures. At the concentrations of TTX used, there was no evidence of direct effects beyond the cochlea and the eighth nerve. We recorded continued activity in nucleus laminaris, which is adjacent to NM and receives input from the contralateral, normal NM. Vestibular areas adjacent to NM also remained active in all experiments. These vestibular neurons remained active despite the fact that their eighth nerve inputs were presumably inactivated as a result of the TTX injection.

Two physiological procedures were used to test whether TTX injections resulted in permanent damage to the cochlea or eighth nerve. In the first, a group of animals was injected with TTX 3 times over $6 \mathrm{hr}$ and then allowed to survive for 1 week. Six animals were tested using far-field evoked potentials to measure auditory threshold frequency functions using tone bursts ranging from $500 \mathrm{~Hz}$ to $4 \mathrm{kHz}$. Average thresholds from stimulation of the TTX-injected side are compared to those from stimulation of the normal ear in Figure 3. At all frequencies tested, the thresholds ipsilateral and contralateral to TTX injection were identical and were comparable to those found in other studies of the chick (Saunders et al., 1973; Kerr et al., 1979; Rebillard and Rubcl, 1981; Tucci and Rubcl, 1985).

We also examined the multiunit activity in NM 1-2 weeks after multiple injections of TTX. Results were the same regardless of the TTX injection schedule ( 3 injections during 6 hr, $n=2$, or 3 injections during $24 \mathrm{hr}, n=3$ ). Representative traces of neuronal activity in NM on both sides of the brain from one animal are shown in Figure 4 . The spontaneous neuronal activity, shown on the left, is similar in both amplitude and spike rate on the 2 sides of the brain. The cvoked multiunit activity, shown on the right, is also similar ipsilateral and contralateral to the TTX injections. Thresholds estimated from rate-intensity functions evoked by tones at $\mathrm{CF}$ were also within $5 \mathrm{~dB}$ SPL in NM on the 2 sides of the brain.

Anatomical tests for degeneration. Two anatomical methods were used to examine whether the TTX injections produced degeneration in the eighth nerve or in NM. Tissue prepared by the method of Fink and Heimer (1967) 1-4 d after 3 injections of TTX at $2 \mathrm{hr}$ intervals showed no silver staining indicative of degeneration in NM or nucleus angularis (another secondorder target of eighth nerve fibers). Both animals that had unilateral cochlea removal showed massive degeneration of the eighth nerve fibers and terminals at these survival times.

Neuron counts and measurement of cross-sectional area were performed on thionin-stained sections from animals receiving multiple injections of TTX ( 3 times in $6 \mathrm{hr}$ ) and allowed to survive for 1 week. For 5 animals, the average difference between NM on the 2 sides of the brain for neuron number was $1.5 \%$ and for soma cross-sectional area, $1.1 \%$. This indicates 


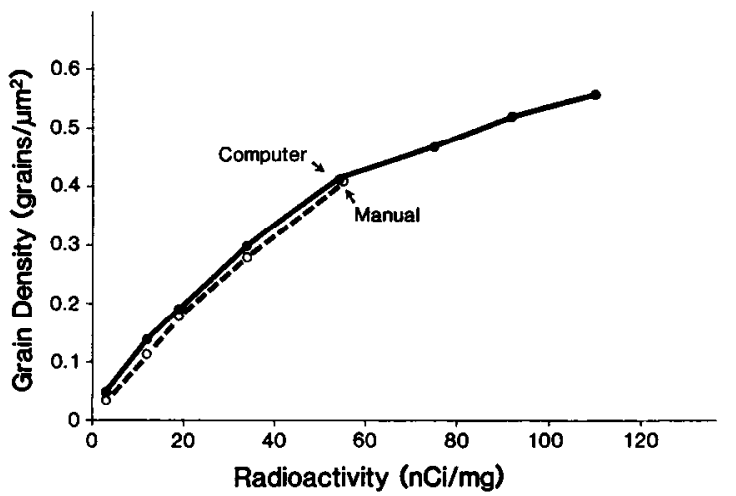

Figure 5. Grain density as a function of the concentration of radioactive isotope in plastic standards. The emulsion was exposed to plastic ${ }^{3} \mathrm{H}$ standards (Amersham) and developed as for the tissue samples. Grains were counted manually (dashed line) and by a computer-controlled detection algorithm (solid line). The grain densities that resulted from both methods were approximately linear from 0.04 to 0.4 grains/ $\mu \mathrm{m}^{2}$. Grain counting above 0.4 grains $/ \mu \mathrm{m}^{2}$ is difficult for the experimenter because of the presence of large numbers of overlapping grains. While the computer continues to report grain densities above 0.4 grains/ $\mu \mathrm{m}^{2}$, these increases are no longer linear with increasing concentrations of radioactivity.

that there were no reliable changes in neuron number or soma size.

\section{Amino acid incorporation}

Grain-counting procedures. Two methods were used to count grains over individual NM neurons (see Materials and Methods). We investigated the linear range of grain densities that could be counted using both techniques by counting grains in emulsion exposed to standards with known concentrations of isotope. Figure 5 shows grain density as a function of the concentration of radioactivity in the standards. Both techniques give increases in grain density that are linear when plotted against increasing concentrations of radioactivity. Difficulty in counting large numbers of frequently overlapping grains forces the experimenter to stop counting at 0.4 grains $/ \mu \mathrm{m}^{2}$. Although the computer does not face this difficulty, increases in radioactivity are not associated with linear increases in grain density beyond approximately 0.4 grains $/ \mu \mathrm{m}^{2}$. Therefore, we considered grain densities above 0.4 grains $/ \mu \mathrm{m}^{2}$ to be beyond the useful range of both counting techniques. Sections with grain densities that exceeded this value were excluded from the analysis.

While the grain counts on standards indicate the linear range of the 2 techniques, they do not indicate that counts made on tissue sections by the 2 techniques would be comparable. We verified the ability of the techniques to give comparabie results by performing counts on 40-50 neurons in the same 12 tissue sections using both the manual and automated techniques. The mean grain density from each section was then calculated and the 2 techniques compared. The 2 methods were highly correlated: the mean grain densities were within $5 \%$; the overall correlation coefficient was 0.9 ; and the grain densities fell closely along a linear regression line with a slope of 0.97 and an intercept of 0.01 . Because this correlation is based on the average grain densities of 40-50 neurons in each of 12 sections, it does not include nearly the full range of grain densities encountered for individual neurons. Thus the correlation we observed is probably a very conservative estimate of the similarity of the 2 measures.
Availability and uptake of ${ }^{3} \mathrm{H}$-leucine. The fixation and tissueprocessing protocol we used was designed to demonstrate only amino acids that were incorporated into proteins. The possibility that TTX injection causes changes in availability or uptake of the protein precursors was studied in 2 unfixed brains. Autoradiograms from these animals $1 \mathrm{hr}$ after a single TTX injection and after 3 injections of TTX during $6 \mathrm{hr}$ showed no apparent difference in labeling over NM neurons on the 2 sides of the brain. The grains were uniformly distributed over the tissue, but there was a sharp boundary at the tissue edges. Grain counts over individual NM somata revealed no consistent differences between the 2 sides of the brain (mean difference, $3.5 \%$ ), supporting our claim that the changes in labeling seen in fixed tissue are due to changes in incorporation of ${ }^{3} \mathrm{H}$-leucine into protein.

Single injections of TTX. The effect of a single TTX injection on the incorporation of ${ }^{3} \mathrm{H}$-leucine into protein is readily apparent upon inspection of the autoradiograms. Figure 6 shows representative autoradiograms and distributions of grain densities from 2 animals that received single injections of TTX. The left panels are from an animal killed $1 \mathrm{hr}$ after the TTX injection and the right panels are from an animal killed $6 \mathrm{hr}$ after the TTX injection. In NM on the side contralateral to the TTX injection in the $1 \mathrm{hr}$ case (Fig. 6A), there is a uniformly high level of labeling over individual NM somata. This indicates that NM neurons are normally actively synthesizing proteins. The autoradiogram from NM ipsilateral to an injection of TTX (Fig. 6B) shows a different pattern of labeling. One hour after TTX injection, there are fewer grains over nearly all neurons, as compared to the contralateral (normal) side. The distributions of grain densities from 40 to 50 neurons on each side of the brain are shown below the auroradiograms (Fig. 6C). This quantitative analysis confirms our impression from the autoradiograms. In NM on the side of the brain contralateral to a single injection of TTX, the grain densities appear normally distributed and have a mean of 0.2 grains $/ \mu \mathrm{m}^{2}$. Grain densities in NM on the side injected with TTX, however, are distributed quite differently. The range is larger and the mean is about 0.1 grains/ $\mu \mathrm{m}^{2}$. These results suggest that there is a rapid and dramatic reduction in amino acid incorporation by NM neurons ipsilateral to a single TTX injection.

By $6 \mathrm{hr}$ after a single injection of TTX, there appears to be considerable recovery in the level of amino acid incorporation among NM neurons. The side contralateral to the TTX injection again shows uniform high levels of grains over individual NM somata (Fig. 6D). On the side of the brain ipsilateral to an injection of TTX (Fig. 6E), the labeling appears to be slightly less dense. The difference in grain densities between the 2 sides of the brain is much less pronounced than at $1 \mathrm{hr}$. Counts of grains over individual neurons and distributions of grain densities from this animal are shown in Figure $6 F$. The distributions of grain densities from the 2 sides of the brain are similar, although the mean of the grain densities from neurons ipsilateral to TTX injection is $15 \%$ lower, which is statistically significant $(p<0.01)$.

Absolute grain densities cannot be compared directly among animals. Therefore, we expressed the mean grain density of NM neurons ipsilateral to the TTX injection as a percentage of the contralateral "control" mean grain density. The individual "percentages of contralateral grain density" for the animals in a group were averaged to give a group mean. Figure 7 shows the mean percentage difference in grain density as a function of time 

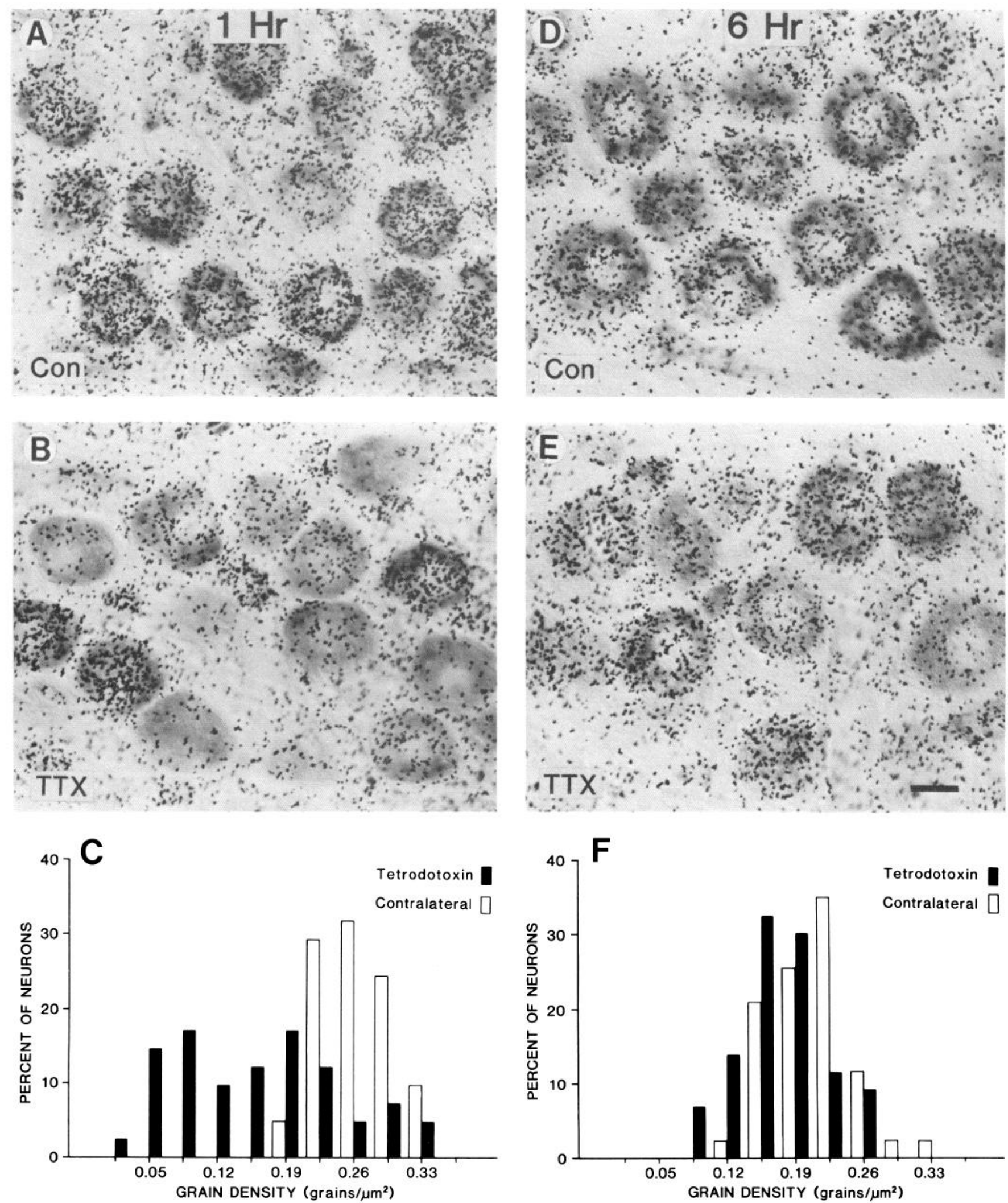

Figure 6. Photomicrographs of autoradiograms and distributions of grain densities from NM on both sides of the brain from 2 animals. On the left are micrographs and distributions from a chicken that received a unilateral injection of TTX $1 \mathrm{hr}$ prior to processing for analysis of amino acid incorporation. $A, \mathrm{NM}$ on the side contralateral to the injection, showing uniformly high labeling over all the neurons. $B$, NM in the same tissue section, ipsilateral to the TTX injection. There are noticeably fewer grains over most of the individual neurons on the side ipsilateral to the injection. $C$, The distributions of grain densities from an adjacent, less heavily labeled section. Neurons on the side contralateral to the injection (open bars) appear to form a homogeneous, normally distributed population. The distribution of grain densities from NM ipsilateral to the TTX injection (solid bars) is broader and appears centered at a much lower grain density. These results are in contrast to those obtained 6 hr after a single injection of TTX (shown on the right). D, Contralateral NM again has uniform dense labeling over all the neurons. $E$, The side ipsilateral to the TTX injection has only slightly fewer grains over the individual neurons. $F$, The distributions confirm the impression of a small difference between the 2 sides. Scale bar, $10 \mu \mathrm{m}$. 


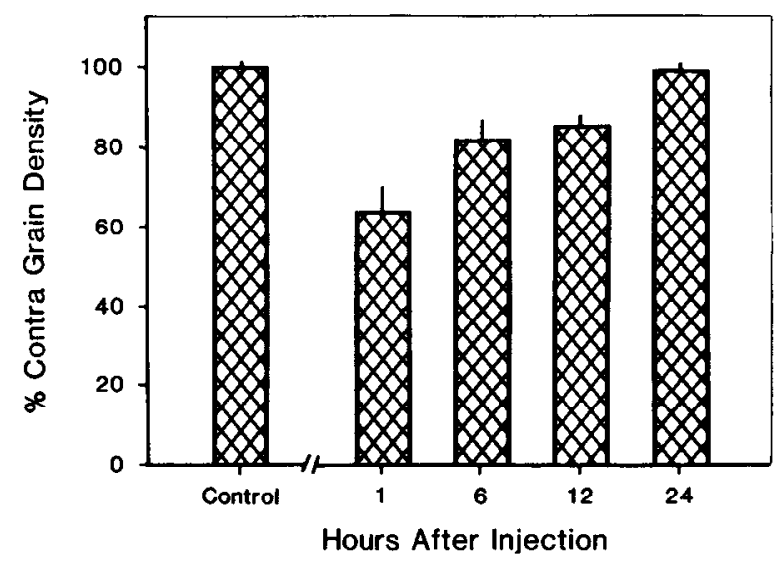

Figure 7. Time course of changes in ${ }^{3} \mathrm{H}$-leucine incorporation by NM neurons after a single injection of TTX. For each animal the average grain density on the side ipsilateral to the TTX injection was expressed as a percentage of the grain density over neurons in the contralateral NM. The group means are plotted as a function of time after the TTX injection. One hour after a single injection of TTX there is a dramatic reduction in ${ }^{3} \mathrm{H}$-leucine incorporation ipsilateral to the injection to $60 \%$ of that found on the contralateral side. There is a steady return of amino acid incorporation to control levels over time. By $24 \mathrm{hr}$ after a single injection, there is no difference between the 2 sides of the brain. Bars indicate SEM. Number of animals in each group: control, 7;1 hr, 6; 6 $\mathrm{hr}, 6 ; 12 \mathrm{hr}, 7$; and $24 \mathrm{hr}, 7$.

after TTX injection. Values for all animals receiving an injection of control substance, either vehicle or acid-inactivated TTX, were pooled since there were no differences between them. The most dramatic effect of eliminating neuronal activity in NM was seen after $1 \mathrm{hr}$ : grain densities were reduced $40 \%$. At longer intervals, the effect of the TTX was less pronounced. By $24 \mathrm{hr}$ after a single injection, there appeared to be no difference between the 2 sides of the brain. These conclusions were confirmed by analysis of variance, which revealed a significant effect of the TTX injcction $(F(4,28)=15.8, p<0.001)$. Individual comparisons indicate that the 1 and $6 \mathrm{hr}$ groups are statistically different from one another and from control animals, whereas the 12 and 24 hr groups are not.

Although mean grain densities reveal the magnitude of the average difference among neurons on the 2 sides of the brain, they do not reveal how the grain densities of individual neurons are distributed within each NM. The distributions of NM grain densities for 6 animals within each group were combined by calculating the standard score for each neuron's grain density (see Materials and Methods). The resulting normalized distributions for animals prepared for analysis of amino acid incorporation 1-24 hr after a single injection of TTX are shown in Figure 8. At $1 \mathrm{hr}$ after TTX injection, neurons on the ipsilateral side form a single population with a range that is considerably larger than that on the side contralateral to the injection. By 6 $\mathrm{hr}$ after an injection there are many fewer neurons in $\mathrm{NM}$ on the injected side with grain densities lower than the contralateral side (Fig. 8). By $24 \mathrm{hr}$ after the TTX injection (Fig. 8), NM neurons ipsilateral to the injection have recovered and the distribution is not different from that on the contralateral side (Fig. 8).

Multiple injections of TTX. Multiple injections of TTX were used to produce a chronic cessation of neuronal activity in NM. We used various intervals between injections in an attempt to produce a chronic activity block. The injections were given at $2 \mathrm{hr}$ intervals for $6 \mathrm{hr}$, at $6 \mathrm{hr}$ intervals for 12 or $24 \mathrm{hr}$, or at
$12 \mathrm{hr}$ intervals for 24 or $48 \mathrm{hr}$ (see Table 1). Additional animals given similar injections of TTX also had the contralateral cochlea removed at the time of the first TTX injection.

When multiple injections of TTX are given at $2 \mathrm{hr}$ intervals, the effect on ${ }^{3} \mathrm{H}$-leucine incorporation $6 \mathrm{hr}$ after the initial injection is considerably different than that seen after a single injection. Autoradiograms from a representative animal given 3 injections of TTX over a $6 \mathrm{hr}$ period are shown in Figure 9. On the side contralateral to the injection, all neurons show uniformly high levels of incorporation (Fig. 9A). On the side ipsilateral to the TTX injections, there appear to be 2 populations of neurons; one group is labeled and a second, distinct group has only background levels of grains (arrowheads, Fig. $9 B$ ). The distributions of grain densities on the 2 sides are strikingly different (Fig. 9C). Neurons on the side injected with TTX can be easily separated into 2 populations on the basis of grain density. One population appears unlabeled, having grain densities of less than 0.05 grains $/ \mu \mathrm{m}^{2}$. The remaining neurons appear to fit a normal distribution, with a mean grain density slightly less than that on the control side.

The normalized distributions shown in Figure 10 were generated by combining standard scores from all 6 animals that were given 3 injections of TTX over $6 \mathrm{hr}$. These group distributions also show that neurons in NM on the side ipsilateral to the TTX injection can be divided into 2 groups. As was seen in the distribution for a single animal (Fig. 9), there is a population that has grain densities that are relatively similar to those found on the contralateral side. A second population of neurons has grain densities that are more than 4 standard deviations below the mean of the control side. The probability that neurons with these low grain densities are part of the more heavily labeled population is statistically virtually nonexistent. Thus, we used the normalized distribution of grain densities to define the population of "unlabeled" neurons as those with standard scores more than 4 standard deviations below the mean on the normal side. When this criterion is applicd to all NM neurons in the individual brains, the "unlabeled" neurons can be removed, and the mean grain densities of labeled neurons alone can be calculated and compared to the normal side. For this analysis, we first computed the mean grain density for all neurons and for labeled neurons only on the side of the brain ipsilateral to the TTX injection. Then the difference between each of these values and the mean grain density on the contralateral side were determined and expressed as a percentage of the grain density on the normal side of the brain (percentage change). The average percentage change in grain density for each group is plotted in Figure 11. A similar calculation from "labeled" neurons $6 \mathrm{hr}$ after cochlea removal is also shown (Steward and Rubel, 1985). Interestingly, the mean change in labeled neurons after cochlea removal was $18 \%$, the same as for "labeled" neurons after TTX blockade.

While the chickens given multiple injections of TTX during a $6 \mathrm{hr}$ period consistently showed reductions in NM amino acid incorporation, chickens given TTX at $6 \mathrm{hr}$ intervals for 12 or $24 \mathrm{hr}$ did not consistently show altered patterns of labeling. Three animals had neurons with grain densities that were clearly unlabeled, while in 2 similarly treated animals this was not the case. In 2 additional animals that also had the contralateral cochlea removed, the changes on the 2 sides of the brain were remarkably similar. In one case, there were numerous unlabeled neurons on both sides of the brain, while in the other, neither side had more than an occasional unlabeled neuron. Because of 

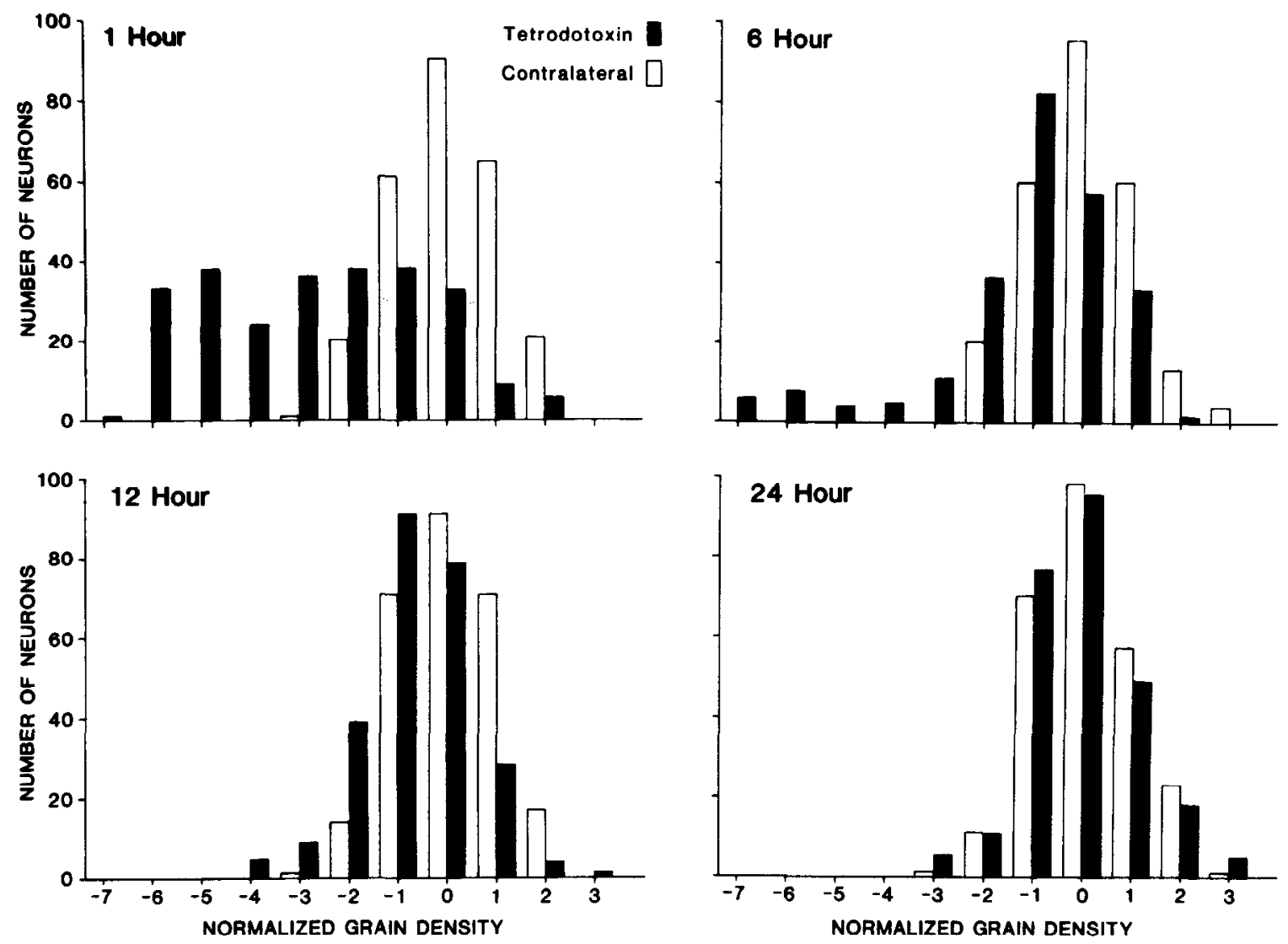

Figure 8. Distributions of normalized grain densities from NM neurons ipsilateral and contralateral to a single injection of TTX 1-24 hr before preparing the animal for analysis of ${ }^{3} \mathrm{H}$-leucine incorporation. Standard scores were calculated for each $\mathrm{NM}$ neuron on both sides of the brain on the basis of the mean and standard deviation of grain densities on the contralateral normal side. Values were obtained from at least 40 neurons on each side of the brain. Thus, each distribution includes more than 480 neurons. The distributions on the side of the brain contralateral to TTX injection (open bars) appear to be normal in all groups. The grain count distribution in NM on the side ipsilateral to an injection of TTX (solid bars) $1 \mathrm{hr}$ before preparation for ${ }^{3} \mathrm{H}$-leucine incorporation is quite broad and appears centered at a much lower grain density. By $6 \mathrm{hr}$ after an injection of TTX, the grain densities ipsilateral to the injection more closely approximate those on the contralateral side, and fewer neurons have low grain densities. This recovery continues at 12 and $24 \mathrm{hr}$ after the TTX injection. By $24 \mathrm{hr}$, the distributions of grain densities on the 2 sides appear to be essentially identical.

the variability between animals, these changes were not quantified. Since the duration of TTX action under these conditions appears to be relatively short, these results are difficult to interpret.

As indicated by the far-field evoked potentials and the results of single TTX injections, the effect of TTX is apparently shortlived when the chickens are not subjected to prolonged anesthesia. We examined this interpretation in an experiment in which 2 TTX injections were given $24 \mathrm{hr}$ apart. One hour after the second TTX injection, these chickens were given an injection of ${ }^{3} \mathrm{H}$-leucine and prepared for autoradiographic analysis. If TTX acts for only a few hours, then additional injections of TTX after $24 \mathrm{hr}$ should produce the samc pattern of changes seen after only a single injection. On the other hand, if there is a residual effect of TTX on NM cells after recovery of the evoked potential and of amino acid in incorporation (Fig. 8), then the second injection, $24 \mathrm{hr}$ after the first, may produce a different pattern of changes in NM neurons. Autoradiograms from the animals given 2 injections of TTX show a remarkably different effect than those of animals given a single injection of TTX and prepared for analysis of amino acid incorporation $1 \mathrm{hr}$ later (Fig. $6 C$ ). On the side ipsilateral to TTX there are a large number of totally unlabeled neurons; this was never observed after a single injection of TTX. Thus, there appears to be some residual action of a single TTX injection even after the apparent recovery of normal physiology and amino acid incorporation.

\section{Further comparisons with cochlea removal}

Short-term changes. In order to make direct comparisons between the effects of TTX injection and of cochlea removal, we examined NM neurons in chickens that were given 3 injections of TTX in one ear during a $6 \mathrm{hr}$ period and had the contralateral cochlea removed at the time of the first TTX injection $(n=6)$. The results of this type of experiment are illustrated in Figure 12. In the autoradiograms (Fig. 12, $A, B$ ), the pattern of silver grains over NM neurons is similar on the 2 sides of the brain. On each side there appear to be 2 populations of neurons. One group is covered with silver grains; a second group is labeled at background levels, indicating that amino acid incorporation has ceased. The distributions of grain densities shown in Figure $12 \mathrm{C}$ provide quantitative confirmation of our observations. From these results we conclude that chronic exposure to TTX for 6 $\mathrm{hr}$, which causes a continuous blockade of NM neuronal activity, produced similar, but slightly less pronounced, changes in amino acid incorporation compared to those observed following cochlea removal. 

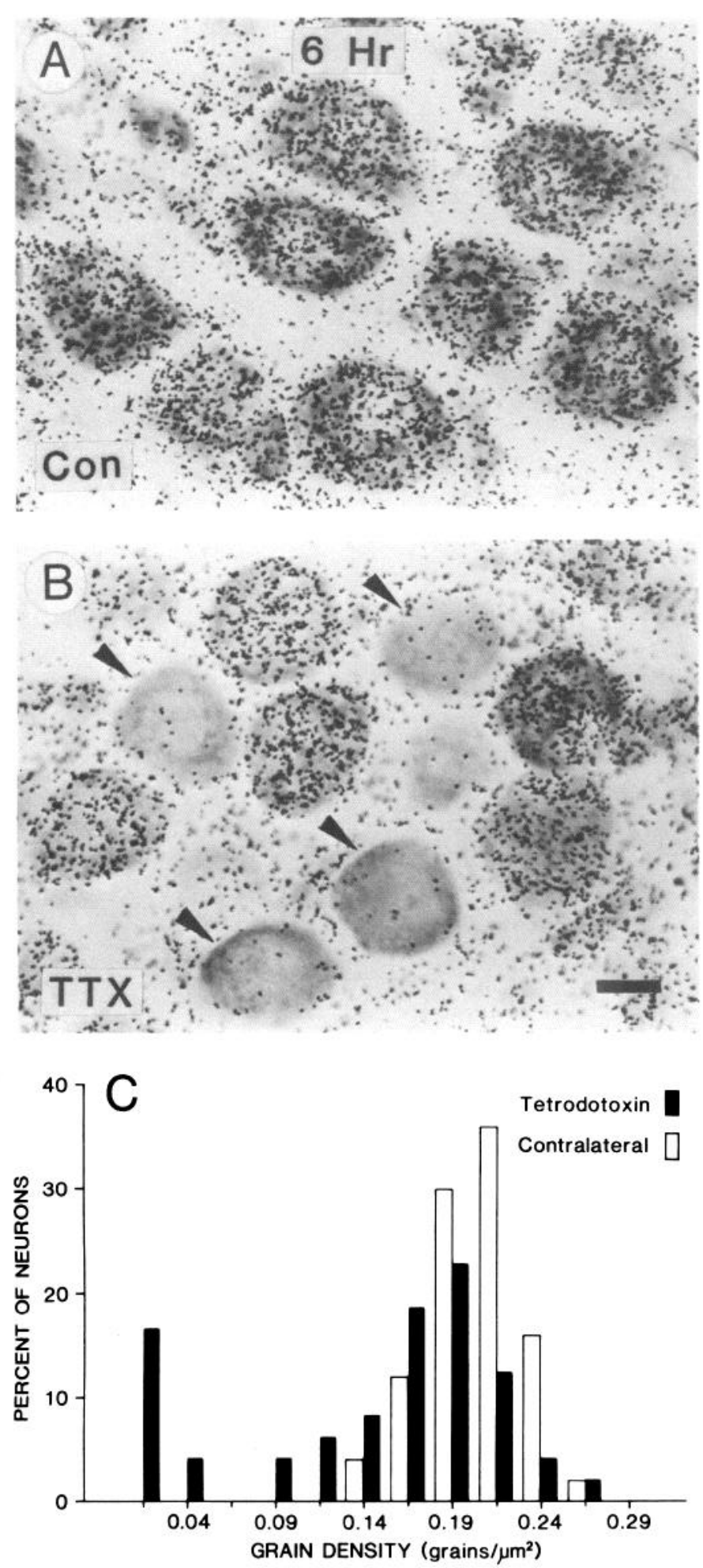

Figure 9. Photomicrographs of autoradiograms and distributions of grain densities from an animal that received 3 injections of TTX during a $6 \mathrm{hr}$ interval prior to being prepared for demonstrating ${ }^{3} \mathrm{H}$-leucine incorporation. $A$, Autoradiogram from NM contralateral (Con) to the injections. As shown in the previous autoradiograms, there is a uniformly high level of labeling over individual NM neurons. $B$, NM on the side ipsilateral to TTX injection. A noticeable paucity of labeling is seen over a portion of the neurons (arrowheads). The remaining neurons appear to be slightly less labeled than those on the contralateral side. $C$, Distributions of grain densities. There are 2 populations of neurons on the side of the brain ipsilateral to the TTX injection. One population has low grain densities, corresponding to the "unlabeled"

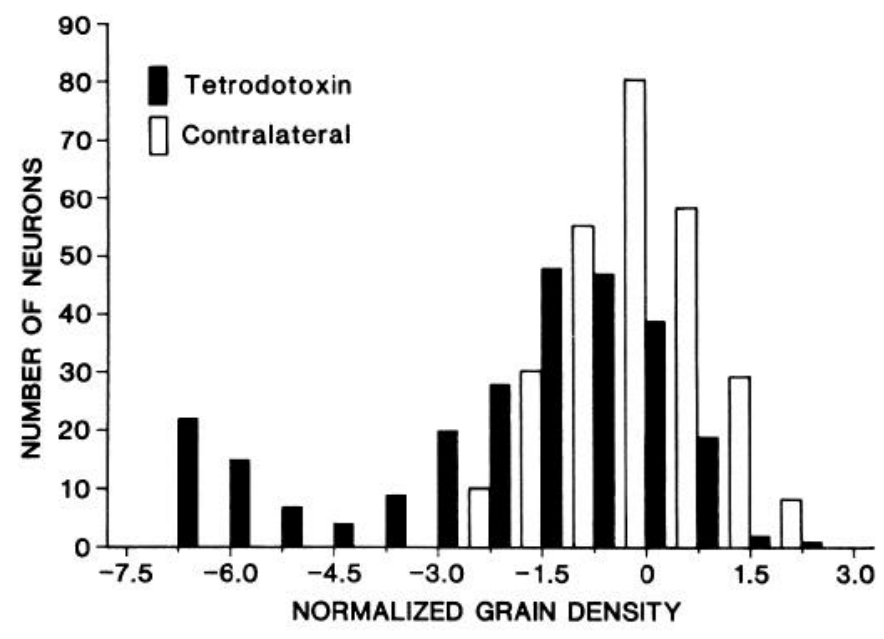

Figure 10. Distributions of normalized grain densities over NM neurons from 6 animals that received 3 injections of TTX at $2 \mathrm{hr}$ intervals. The standard scores on both sides of each brain were calculated as in Figure 8. The distribution of grain densities of NM neurons on the side ipsilateral to TTX injection (open bars) can be divided into 2 populations. One population, with grain densities more than 4 SDs below the mean on the normal side, represents "unlabeled" samples. These neurons constitute about $20 \%$ of the neurons.

Long-term changes. Although the rapid change in amino acid incorporation may predict the long-term consequences of TTX injections, we wished to examine directly the effects of intermittent long-term activity blockade on the morphological characteristics of NM neurons. TTX injections were repeated 4 times during a $48 \mathrm{hr}$ period ( $12 \mathrm{hr}$ intervals). Each injection probably eliminated activity in the eighth nerve and NM for approximately $6 \mathrm{hr}$. The results of neuron counts and measures of soma cross-sectional area are plotted in Figure 13, along with data from a similar survival period following cochlea removal (Born and Rubel, 1985). Forty-eight hours of chronic exposure to TTX produced transneuronal degeneration of $20.3 \%$ neurons and an $8.3 \%$ atrophy of the remaining neurons, as compared with 28 and $13 \%$, respectively, following cochlea removal. The magnitude of these morphological changes is similar to that at $48 \mathrm{hr}$ following cochlea removal. Statistical comparisons support the conclusion that TTX injections and cochlea removal produced similar losses of NM neurons $(t=1.08, p>0.1)$ and similar changes in soma cross-sectional area $(t=1.48, p>0.1)$.

Additional qualitative similarities between the effects of multiple TTX injections and cochlea removal were observed. Figure $14 A$ shows a photomicrograph from NM on the side of the brain ipsilateral to TTX injections that were given 4 times during a $48 \mathrm{hr}$ period. While many neurons have uniformly dense Nissl staining, a subpopulation (approximately 25\%) appears relatively unstained. Similar unstained neurons, termed "ghost" neurons, were observed $2 \mathrm{~d}$ after cochlea removal (Born and Rubel, 1985).

Finally, it is interesting to compare the soma sizes of 2 animals that were both given unilateral TTX injections for $2 \mathrm{~d}$ but showed marked differences in the effects of TTX on incorporation of

neurons seen in the micrographs. A second population has grain densities that are comparable to those of the contralateral normal side, although the mean appears lower than on the contralateral side. Scale bar, $10 \mu \mathrm{m}$. 


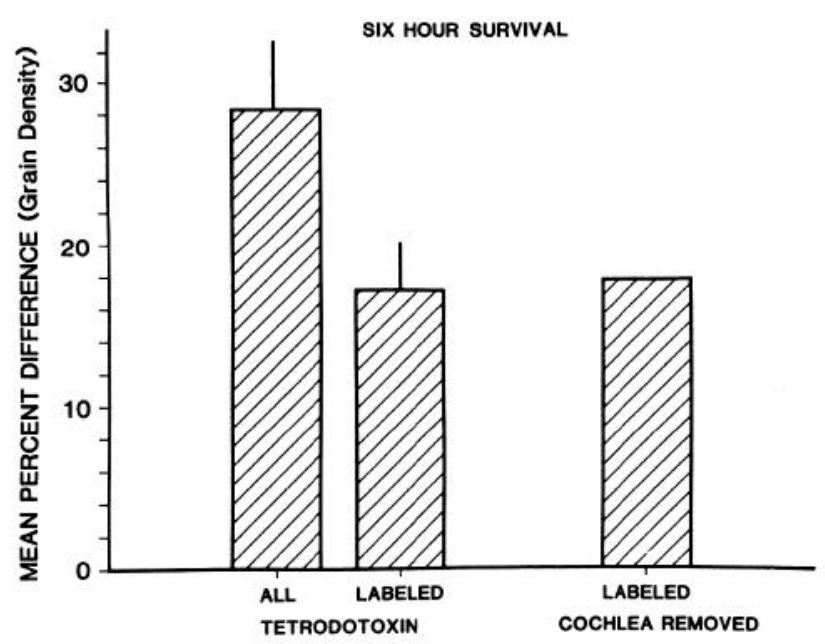

Figure 11. The mean percentage decrease in grain density after cochlea removal or multiple TTX injections (3 injections in $6 \mathrm{hr}$ ). For each animal the difference in average grain density between NM neurons on the 2 sides of the brain was expressed as a percentage of the grain density on the normal side. The average grain density in the TTX group was calculated either for all NM neurons on the experimental side or for only "labeled" neurons. Also plotted is the mean percentage grain density difference for "labeled" neurons following cochlea removal (from Steward and Rubel, 1985).

amino acid. NM neurons from the animal that showed significantly decreased label were $12.3 \%$ smaller $(p<0.01)$ than their contralateral counterparts. However, in the other animal, in which the neurons showed no reliable change in grain density, there was only a $3.1 \%$ decrease in soma cross-sectional area, which was not statistically reliable. Thus, in this example, soma cross-sectional area changes are correlated with grain-density changes, and therefore appear to be a good indicator of underlying protein-synthetic rates.

\section{Discussion}

To examine the presynaptic signals responsible for neuron loss and atrophy following cochlea removal, we used an approach commonly employed to investigate the regulation of muscle by motor nerves. Eighth nerve action potentials were blocked by injecting TTX into the perilymph, which bathes the distal processes of the ganglion cells and the basal part of the hair cells. When TTX injections produced a chronic block of neuronal activity in NM, we observed reductions in amino acid incorporation, neuron number, and neuron size equivalent to those seen following cochlea removal. Unlike cochlea removal, however, the activity block produced by TTX injection was reversible. By $24 \mathrm{hr}$ after a single injection of TTX, amino acid incorporation in NM had returned to normal. The similarity between the postsynaptic consequences of cochlea removal and selective blockade of neuronal activity suggests that activity or activity-coupled release of some molecule is an important presynaptic signal regulating the postsynaptic consequences of denervation.

The discussion that follows first examines aspects of the methods that are important for interpreting the results. Next, the contribution of neuronal activity to the regulation of target neurons is considered. Finally, some issues related to the mechanisms by which activity blockade influences target neurons are discussed.
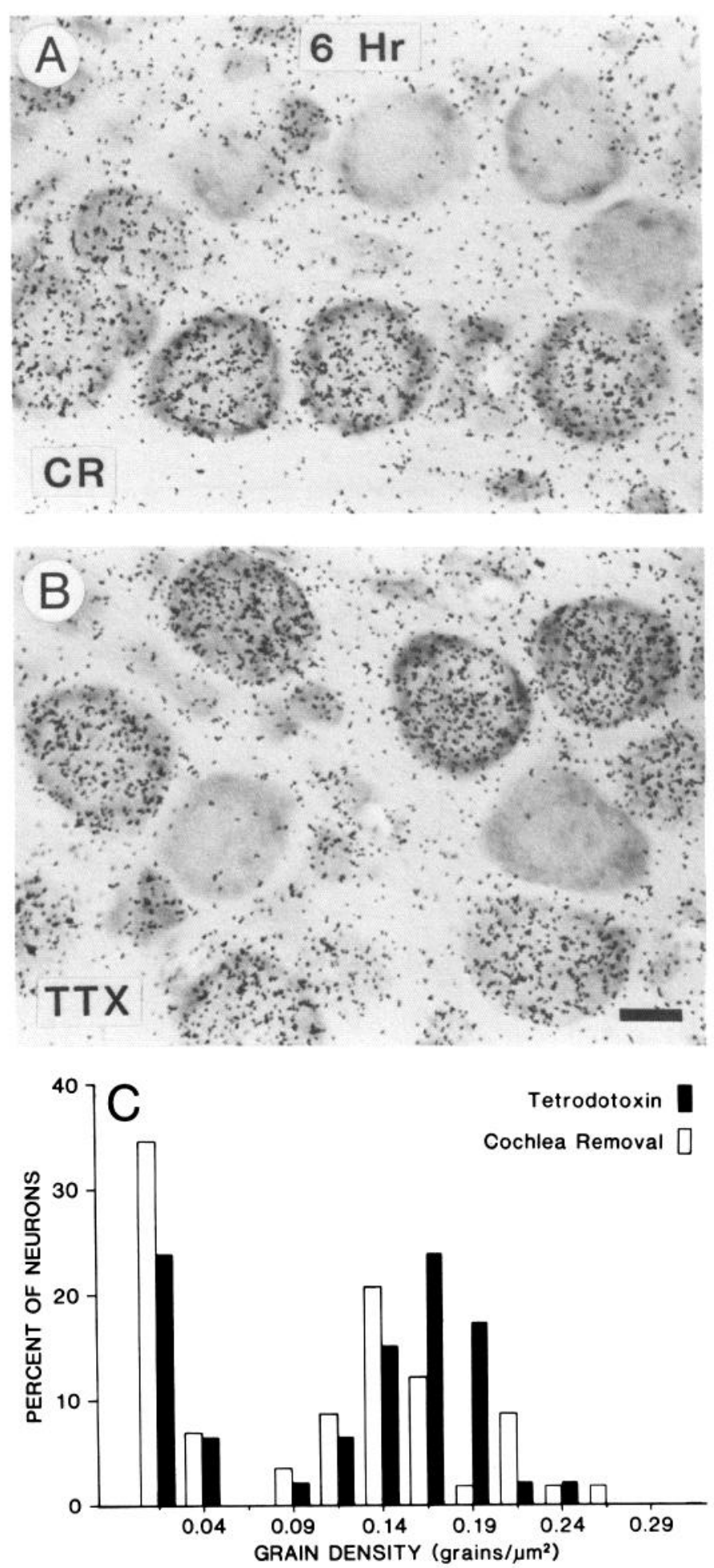

Figure 12. Photomicrographs of autoradiograms and distributions of grain densities from a chicken that had one cochlea removed and received 3 injections of TTX in the other cochlea during a $6 \mathrm{hr}$ interval. The contralateral cochlea was removed at the time of the first TTX injection. The autoradiograms on the side of the cochlea removal $(A$, $C R)$ and on the side of the TTX injections $(B, T T X)$ show that a subsample of NM neurons is devoid of silver grains. A second group of neurons on both sides is characterized by uniform labeling over the somata. The distributions shown in $C$ support the same conclusion. There are 2 distinct populations on both sides of the brain. Scale bar, $10 \mu \mathrm{m}$. 


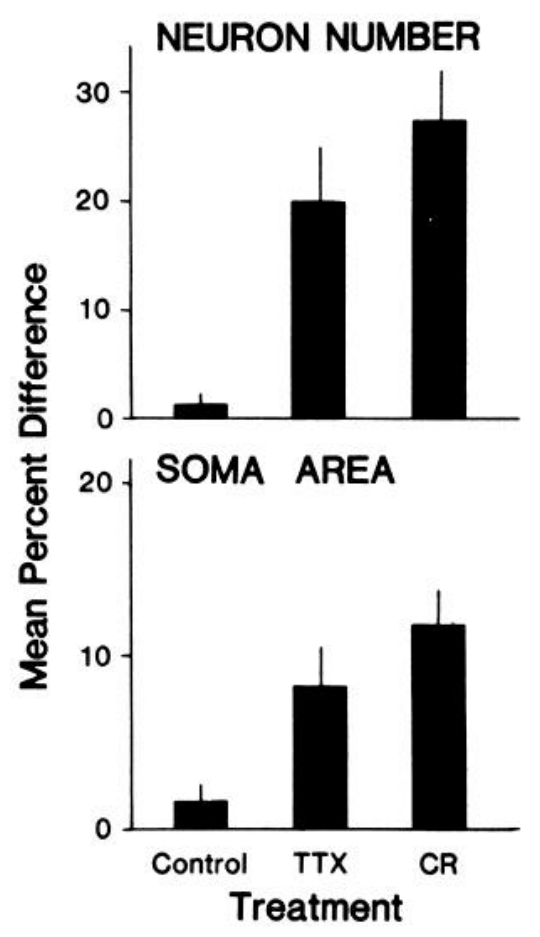

Figure 13. Mean percentage difference in neuron number and soma cross-sectional area between NM neurons on the 2 sides of the brain. Height of bars indicates percentage decrease due to $48 \mathrm{hr}$ of chronic exposure to TTX $(n=6)$ or to $48 \mathrm{hr}$ after cochlea removal $(n=5$; Born and Rubel, 1985). Control animals $(n=3)$ of the same age were unoperated. Bars equal 1 SEM. The differences between animals that were subjected to cochlea removal and those receiving TTX injections are not statistically significant, but both are reliably different from control animals $(p<0.01)$.

\section{Methodological considerations}

Effects of TTX. TTX binds selectively to voltage-activated $\mathrm{Na}^{+}$ channels and in this way blocks the conduction of action potentials (Narahashi et al., 1964; Nakamura et al., 1965; reviewed in Hille, 1968; Evans, 1972). In the present study, injections of TTX into the perilymph caused a rapid and total elimination of action potentials in the eighth nerve and NM. Except for a slight delay during which the toxin diffuses through the perilymph, the loss of activity in NM appears to be identical to that following cochlea removal (Born and Rubel, 1984). Potentials recorded with tungsten microelectrodes in NM following an injection of TTX were not noticeably different from electrical noise recorded in the cerebrospinal fluid above the brain.

Our analysis is based on the assumption that TTX is acting on the eighth nerve. To demonstrate that TTX was not diffusing directly into the brain stem, we recorded from nuclei surrounding NM following TTX injection. Normal spontaneous activity was recorded in the adjacent nucleus laminaris, which receives a normal input from the uninjected ear via the contralateral NM. We also recorded spontaneous discharges from adjacent vestibular nuclei. Continued activity in vestibular nuclei was also seen following cochlea removal (Born and Rubel, 1984). These neurons also receive input from eighth nerve fibers that have been silenced by the TTX injection. Continued activity of brain stem vestibular neurons could be due to other excitatory inputs or to intrinsic mechanisms (Hyson and Rubel, 1986). In addition to diffusing into the brain stem, TTX could act sys-
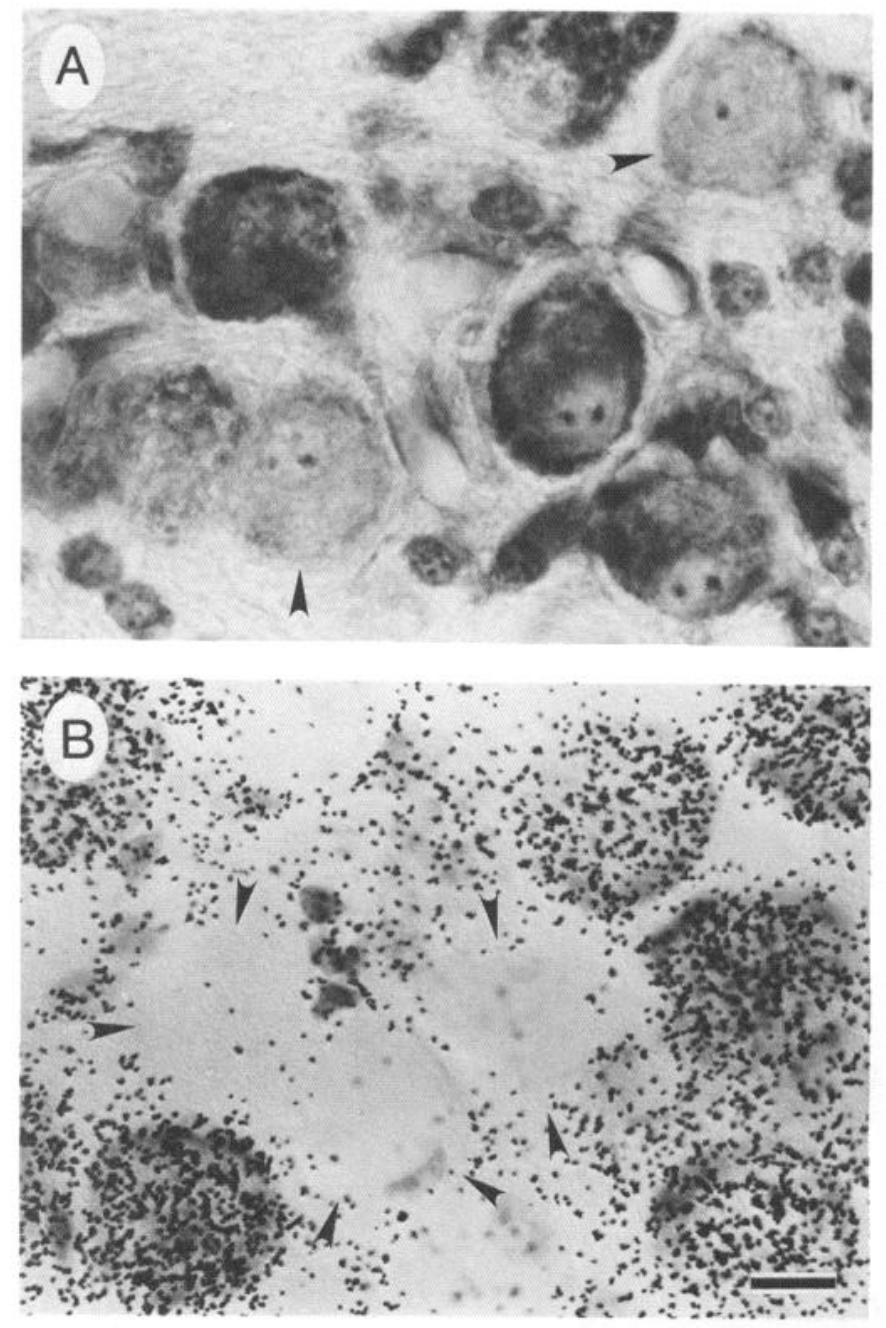

Figure 14. Photomicrographs of thionin-stained sections prepared for routine light-microscopic examination $(A)$ and from another animal prepared for autoradiographic demonstration of amino acid incorporation $(B)$. Both animals were subjected to chronic TTX block for $2 \mathrm{~d}$. In $A$ there are neurons whose cytoplasm is devoid of Nissl staining (arrowheads). These neurons are detectable because of the presence of nuclear and cytoplasmic membranes and the staining within the nucleus. In the autoradiogram, areas strikingly devoid of grains can be identified. These clear areas always appear over unstained neurons, indicating that the unlabeled and unstained neurons are the counterpart of the "ghost" neurons shown in $A$. Bar, $10 \mu \mathrm{m}$.

temically. However, neither unlabeled neurons nor "ghost neurons" were ever seen in NM contralateral to TTX injections. Therefore the changes in NM neurons following TTX injection are not likely to be caused by diffusion of TTX into the brain stem or by systemic effects of TTX.

Other investigators using TTX doses similar to those used here have not observed direct toxic effects of TTX on CNS neurons (Boss and Schmidt, 1984; Reh and Constantine-Paton, 1985). We tested for this possibility by allowing animals to recover for 1-2 weeks following multiple TTX injections. Evoked potential thresholds as well as extracellularly recorded activity levels in NM were then examined. A deficit at any peripheral site would produce altered thresholds or spike rates. These physiological measures of auditory function revealed no detectable deficit. Thus, the long-term integrity of the inner ear appears unaffected by the injections. Tissue prepared to demonstrate 
degenerating nerve terminals provided further support for this conclusion, since there was no evidence of degenerating eighth nerve axons or terminals at any time after the TTX injections.

One caveat is needed when considering the use of selective action potential blockade with TTX. While there is ample evidence that bulk transport of proteins is not affected by blocking action potentials (Pestronk et al., 1976; Lavoie et al., 1977; Grafstein et al., 1981), there is some evidence that, in goldfish, the transport of nucleosides to the optic tectum may be reduced after $2 \mathrm{~d}$ of intraocular injections of TTX (Edwards and Grafstein, 1986). If such changes in transport affect "trophic" substances that might play a role in maintaining target neurons, then interpreting the results of experiments using "selective" activity blockade will be more difficult.

Recovery. The major physiological difference between cochlea removal and injections of TTX is the reversibility of the activity block produced by TTX injection. Evoked activity can be detected in the auditory system of some animals within $6 \mathrm{hr}$ after a single TTX injection. It is difficult to say what level of spontaneous activity would be found in NM, since this is not a direct measure. Concurrent recording of far-field evoked potentials and neuronal activity in NM after TTX injection showed that changes in sound-evoked potentials were precisely coincident with the elimination of activity. In the visual system as well, the return of evoked potentials in response to light flashes was highly correlated with the return of action potentials recorded in the lateral geniculate nucleus (LGN) of cats following TTX injections into the eye (Dubin et al., 1986).

The rapidity of the recovery in the auditory system was surprising. In the peripheral nervous system, single injections of TTX into the perineurium surrounding motor nerves can produce a conduction block that lasts for as long as 2-2.5 d (Pestronk et al., 1976; Butler et al., 1978). Similarly, injections of $1-10 \mu \mathrm{g}$ of TTX into the fluid-filled vitreous of the eyes of frogs or cats cause $2-4 \mathrm{~d}$ of retinal ganglion cell inactivity, as assayed by visual reflexes (Edwards and Grafstein, 1983; Kupperman and Kasamatsu, 1983; Meyer, 1983; Reh and Constantine-Paton, 1985; Dubin et al., 1986; Stryker and Harris, 1986). In light of these results, our finding that evoked activity returned within $6 \mathrm{hr}$ after TTX injection was unexpected. However, in the examples given above, TTX was injected into a closed space that could act as a reservoir. In preparations of isolated squid or frog nerves the effects of TTX were found to be largely reversed within 3-10 min after the nerve was placed in drug-free medium (Nakamura et al., 1965; Schwartz et al., 1973). The perilymph of the vestibular labyrinth into which we injected TTX is a metabolically active fluid (similar to cerebrospinal fluid); it is likely that TTX was metabolized or eliminated with the turnover of perilymph. Consequently, recovery from the effects of TTX would occur as the concentration of drug decreased. The turnover of perilymph in the avian basilar papilla has not been investigated to our knowledge.

\section{Neuronal activity and neuron loss}

In the present study, TTX injections produced rapid and dramatic changes in NM neurons. Both the short-term (1 hr) and long-term (6-48 hr) consequences of action potential blockade on amino acid incorporation, neuron survival, and neuron soma size were similar to those following cochlea removal. Qualitative and quantitative similarities in the response to these 2 manipulations suggest that it is the elimination of eighth nerve action potentials following cochlea removal that is responsible for the structural and metabolic changes in NM neurons. Obviously this conclusion is based on the examination of only a limited subset of cellular events. There are likely to be other posisynaptic properties that are regulated by other aspects of the presynaptic input (Younkin et al., 1978; McArdle, 1983).

Consequences of activity changes in other systems. The regulatory role of neuronal activity transmitted from presynaptic neurons has been best studied at nerve-muscle synapses. Motor nerve activity blockade produced by applying TTX causes decreased resting membrane potentials and increased sensitivity to acetylcholine (Pestronk et al., 1976; Lavoie et al., 1977). These changes occur without signs of degeneration in the motor nerve. Studies of naturally occurring neuron death during early development of the nervous system suggest a clear role of afferent input (Levi-Montalcini, 1949; Parks, 1979; Okado and Oppenheim, 1984; Clarke, 1985; Furber et al., 1987). There is some evidence that afferent neuronal activity is important in this effect (Chiappinelli et al., 1978; Wright, 1981; Maderdrut et al., 1984). In the central nervous system of more mature animals, neurons in the LGN have been studied following intraocular injections of TTX (Kupperman and Kasamatsu, 1983; Wong-Riley and Riley, 1983; Wong-Riley and Carroll, 1984; Chapman et al., 1986, Dubin et al., 1986). Extracellular recordings from microelectrodes located in the LGN confirm that the TTX injection caused complete cessation of action potentials (Dubin et al., 1986). Kupperman and Kasamatsu (1983) examined neurons in the lateral geniculate of 7-week-old kittens or adult cats after 1 week of action potential blockade. Neurons in the LGN layers connected the injected eye were $20-30 \%$ smaller than those in layers innervated by the normal eye. Neuron size returned to normal 3 weeks after TTX injections were stopped. A more pronounced effect on cell size was observed when kittens were given TTX injections for 10 weeks, starting shortly after birth (Dubin et al., 1986). Even when the injections of TTX were followed by a recovery period of up to $200 \mathrm{~d}$, there was still a reduction in the size of neurons receiving input from the previously injected eye. In these investigations, the long-term application of TTX was associated with shrinkage of the retinal ganglion cells, although there was no ganglion cell loss. In addition to the morphometric effects, action potential blockade causes changes in metabolic enzymes in LGN neurons. After 1-6 weeks of monocular action potential blockade in adult cats there is a reversible decrease in cytochrome oxidase (CO) levels (Wong-Riley and Riley, 1983), and $1 \mathrm{~d}$ after monocular injection of TTX in monkeys there are $\mathrm{CO}$ activity decreases in LGN neurons (Wong-Riley and Carroll, 1984). Changes in LGN neurons after intraocular injections of TTX were similar, but not identical, to those seen in NM neurons after TTX injection. In both cases there was soma shrinkage in the inactive neurons. However, transneuronal cell loss has not been reported in the LGN (Kupperman and Kasamatsu, 1983; Dubin ct al., 1986). An important difference between the neurons in the LGN and those in NM is the proximity of other active inputs to the LGN. Following TTX injection, terminals of ganglion cells from the uninjected eye are thought to innervate some of the inactive LGN neurons (Dubin et al., 1986). The apparent lack of such "alternative input" in NM may explain why many NM neurons die after TTX injection.

Comparison with deprivation experiments. Sensory deprivation studies have attempted to demonstrate how experience regulates central nervous system development. The underlying 
assumption of such experiments is that sensory deprivation produces a selective decrease in the amount or pattern of neuronal activity (Globus, 1975). Therefore, it is interesting to compare the results of experiments that directly manipulate neuronal activity (e.g., by TTX injection) with those that manipulate an organism's interaction with its environment.

Acoustic information reaching the inner ear has been manipulated in a variety of ways, including rearing animals in quiet (Webster and Webster, 1979), removing the anlagen of the external auditory meatus (Webster, 1983), suturing the external auditory meatus (Silverman and Clopton, 1977), removing the ossicle(s) (Tucci and Rubel, 1985), or plugging the external auditory meatus with wax or silicone impression rubber (Kerr et al., 1979; Feng and Rogowski, 1980; Smith et al., 1983). Each of these manipulations effectively attenuates sound, thereby altering at least the pattern of impulses in the eighth nerve. In addition, each has been reported to result in abnormal central nervous system structure or function. On the other hand, several experiments have been reported in which such manipulations resulted in little or no change (Liberman, 1978; Tucci and Kubel, 1985) or in complex changes difficult to relate simply to the amount of acoustic attenuation (Smith et al., 1983). Rclativcly little information is available on the precise nature of the activity changes produced by each of the above manipulations. Our previous investigations suggest that, in the chick brain stem, acoustically driven activity plays little or no role in the maintenance of normal cell morphology. Instead, measurements of spontaneous activity could be positively related to changes in NM cell size and nuclear morphology (Tucci and Rubel, 1985; Tucci et al., 1987). That is, removal of the middle ear ossicle (columella) results in a conductive hearing loss of about $50 \mathrm{~dB}$, but does not significantly alter spontaneous activity in NM and does not significantly influence NM neuron soma size. The same manipulation coupled with production of an oval window fistula, however, causes a marked reduction of spontaneous discharges in the eighth nerve and NM without apparent structural damage to the hair cells of the cochlear partition. In this case, marked changes in soma size and nuclear morphology are evident. These results, coupled with the present findings, strongly suggest that acoustically driven activity is not necessary for the maintenance of postsynaptic cell morphology. Spontaneous activity generated in the cochlear partition or eighth nerve appears sufficient to maintain normal postsynaptic cellular integrity.

A similar conclusion appears warranted by studies of the visual system. Recent experiments comparing the effects of intraocular TTX injections in cats and frogs support the view that segregation of retinal afferents in the frog tectum (Boss and Schmidt, 1984; Reh and Constantine-Paten, 1985), cat LGN (Dubin et al., 1986), and cat cerebral cortex (Chapman et al., 1986; Stryker and Harris, 1986) depends on the balance of absolute levels of activity in the optic pathways emerging from the 2 eyes. One important difference between these areas of the visual system and NM is the convergence of dissimilar afferents onto tectal, geniculate, and cortical cells. In this case, it appears that when activity in 2 or more afferents is unequal, segregation will favor the more active fibers. This hypothesis suggests that monocular deprivation causes a significant reduction in but does not abolish, activity from the deprived eye.

Unfortunately, there are only a few direct measurements of overall activity changes due to lid suture or dark conditions (Rodieck, 1967; Burke and Hayhow, 1968), and essentially nothing is known about ongoing activity levels under such con- ditions. Furthermore, were such results readily available, prediction of the results of deprivation experiments would remain complicated by several factors. First, we have little information on the degree or the duration of activity change that would result in postsynaptic alterations or provide a "competitive advantage" to converging afferents. Second, numerous studies show that the effects of such manipulations can be markedly different hetween young and adult animals. As yet we have little information on the cellular properties underlying such a difference. Recent experiments in which we assessed the changes in NM activity resulting from damage to the auditory periphery indicate little or no difference between young and adult chicks (D. E. Born and D. Durham, unpublished observations), although the postsynaptic morphological consequences were strikingly different (Born and Rubel, 1985; Durham and Rubel, 1985a, b).

\section{Mechanisms of action}

The results of experiments in which neuronal activity is selectively blocked suggest that many neurons are dependent on presynaptic activity to maintain normal metabolic function. The mechanism through which neuronal activity has this effect on postsynaptic neurons has received relatively little attention. It is not clear, for example, whether it is activity in the presynaptic terminal or the postsynaptic target that is necessary for maintaining the target. This question has been addressed in studies of nerve muscle interactions by directly stimulating muscle fibers following denervation (Drachman and Witzke, 1972; Purves and Sakmann, 1974; Lomo and Westgaard, 1975). Muscle stimulation largely reverses the increase in sensitivity to acetylcholine and the decrease in resting membrane potential seen following denervation (Drachman and Witzke, 1972; Lomo and Westgaard, 1975). Interestingly, one consequence of denervation, the development of intermittent spontaneous action potentials, should act to reduce the effects of denervation. Purves and Sakmann (1974) found that denervated muscle fibers in culture were intermittently spontaneously active. Direct stimulation of these fibers led to long periods without spontaneous activity and reductions in abnormal acetylcholine sensitivity (Purves and Sakmann, 1974). It is possible to directly stimulate axons of NM neurons in order to antidromically stimulate the soma. If postsynaptic activity, per se, is necessary and sufficient for maintaining NM neurons, then antidromic activation following cochlea removal or TTX injections should eliminate the reductions in amino acid incorporation and neuron loss reported here.

While the effects of denervating muscles can be largely reversed by direct electrical stimulation, certain properties, such as acetylcholinesterase enzyme levels, do not return to normal (Lomo and Rosenthal, 1972). For this reason, presynaptic activity is thought to be important, independent of its role in evoking action potentials in the postsynaptic target. In the chick auditory system, it is equally important to distinguish the specific activity-related change in presynaptic elements that produces the postsynaptic effect. One possibility is that some effect of activity-dependent transmitter release, other than the generation of postsynaptic action potentials, regulates the postsynaptic neuron. For example, ion fluxes or a second messenger could be triggered by transmitter binding to the postsynaptic receptors (Betz and Changeaux, 1979). Alternatively, "trophic" substances could be released from the presynaptic neuron simultaneously with neurotransmitter. Such substances could be 
necessary for maintaining the postsynaptic neuron, possibly via a specific receptor. Examples of colocalization of peptides and other presumptive transmitters are now common. In addition, evidence that adenosine is released in an activity-dependent manner (Edwards and Grafstein, 1986) raises intriguing possibilities.

The experiments reported here address the influence of neuronal activity on target cell anatomy. We have noted a close correlation between presynaptic activity, changes in amino acid incorporation, and morphometric changes, such as neuron size or number. Several issues related to the mechanisms whereby presynaptic activity acquires these influences remain unresolved and warrant brief consideration. First, what is the cellular chain of events that leads to rapid decreases in protein synthesis, with ensuing cellular atrophy or cell death? We have investigated only a limited subset of neuronal changes in the present study. Observations of other temporally correlated changes in NM neurons following cochlea removal or TTX injections may help elucidate the sequence of cellular events. Most parameters thus far examined decrease following such manipulations. These include 2-deoxyglusose incorporation (Lippe et al., 1980) and immunocytochemical staining for tubulin, actin, and MAP-2 (Seftel et al., 1986). On the other hand, studies of metabolic enzymes, such as succinate dehydrogenase, malate dehydrogenase, and lactate dehydrogenase indicate an initial increase in activity that is followed by a long-term decrease (Durham and Rubel, 1985a, b; Durham et al., 1985). These results argue against a passive decrease in metabolic function. This pattern of cellular changes is reminiscent of those reported in insect muscle and nervous system during normal embryonic cell death and after steroid manipulation (Stocker et al., 1978; Truman, 1984). Some evidence suggests that, in these cases, programmed cell death is due to the expression of a protein that actively destroys the cells' protein-synthesizing machinery (Lockshin, 1969; Horvitz et al., 1982; Truman and Schwartz, 1984). Recent electron-microscopic studies in our laboratory suggest that a similar mechanism may be responsible for transneuronal degeneration of NM neurons (E. W Rubcl and O. Steward, unpublished observations).

Another issue deserving comment is the bimodal response of NM neurons following TTX injections or cochlea removal (Born and Rubel, 1985; Steward and Rubel, 1985). Approximately one-third of the neurons cease making proteins and degenerate. The other two-thirds atrophy but do not degenerate. The cellular properties that separate cells that will degenerate from the remainder are not clear. Differences in innervation or activity after the manipulation do not appear to be responsible. Neither physiological nor morphological analysis has revealed 2 distinct classes of NM neuron (Rubel and Parks, 1975; Parks, 1981). In fact, at this time it is not known whether the final distribution of neurons destined to degenerate is stochastic or predetermined in some way. To answer this question, it may be useful to determine whether there is initially a uniform response of NM neurons to afferent activity block. Following cochlea removal, it appeared that the amino acid incorporation was uniformly decreased at very short survival times (Steward and Rubel, 1985), indicating that the "decision" to degenerate or atrophy is secondary to an initially uniform reaction.

Finally, the results of this study indicate that activity is an important signal for neuron regulation, but they provide no evidence regarding the shape of the function relating incorporation to activity. Is it linear, or is there some threshold amount of activity for maintaining the normal viability of NM neurons? Recently, we have shown that the results obtained in vivo can be mimicked using electrical stimulation in a brain stem slice maintained in vitro (Hyson and Rubel, 1986). This preparation has the advantage that eighth nerve activity can be directly and parametrically controlled. It should prove valuable for further understanding of the cellular mechanisms and temporal properties of interneuronal metabolic regulation.

\section{References}

Albuquerque, E. X., J. E. Warnick, J. R. Tasse, and F. M. Sansome (1972) Effects of vinblastine and colchicine on neural regulation of the fast and slow skeletal muscle of the rat. Exp. Neurol. 37: 607634.

Betz, H., and J.-P. Changeux (1979) Regulation of muscle acetylcholine receptor synthesis in vitro by cyclic nucleotide derivatives. Nature 278: 749-752.

Boord, R. L., and G. L. Rasmussen (1963) Projection of the cochlear and lagenar nerves on the cochlear nuclei of the pigeon. J. Comp. Neurol. 120: 463-475.

Born, D. E., and E. W Rubel (1984) Cochlea removal eliminates physiological activity in brain stem auditory nuclei of the chicken. Soc. Neurosci. Abstr. 10: 843.

Born, D. E., and E. W Rubel (1985) Afferent influences on brain stem auditory nuclei of the chicken: Neuron number and size following cochlea removal. J. Comp. Neurol. 231: 435-445.

Boss, V. C., and J. T. Schmidt (1984) Activity and the formation of ocular dominance patches in dually innervated tectum of goldfish. J. Neurosci. 4: 2891-2905.

Breeden, T. M., W. M. Petroll, D. E. Born, and A. Anne (1986) Grain counting with the Gould IP8500 image processing system. 39th Annual Conference on Engineering in Medicine and Biology, Baltimore, MD.

Buller, A. J., J. C. Eccles, and R. M. Eccles (1960) Interactions between motoneurons and muscles in respect of the characteristic speeds of their responses. J. Physiol. (Lond.) 150:417-439.

Burke, W., and W. R. Hayhow (1968) Disuse in the lateral geniculate nucleus of the cat. J. Physiol. (Lond.) 194: 495-519.

Butler, I. J., D. B. Drachman, and A. M. Goldberg (1978) The effect of disuse on cholinergic enzymes. J. Physiol. (Lond.) 274: 593-600.

Chapman, B., M. D. Jacobson, H. O. Reiter, and M. P. Stryker (1986) Ocular dominance shift in kitten visual cortex caused by imbalance in retinal electrical activity. Nature $324: 154-156$.

Chiappinelli, V. A., K. Fairman, and E. Giacobini (1978) Effects of nicotinic antagonists on the development of the chick lumbar sympathetic ganglia, ciliary ganglion and iris. Dev. Neurosci. 1: 191-202.

Clarke, P. G. H. (1985) Neuronal death during development in the isthmo-optic nucleus of the chick: Sustaining afferents from the tectum. J. Comp. Neurol. 234: 365-379.

Close, R. (1969) Dynamic properties of fast and slow skeletal muscles of the rat after nerve cross-union. J. Physiol. (Lond.) 204: 331-346.

Cowan, W. M. (1970) Anterograde and retrograde transneuronal dcgeneration in the central and peripheral nervous system. In Contemporary Research Methods in Neuroanatomy, W. J. H. Nauta and S. O. E. Ebbesson, eds., pp. 217-251, Springer-Verlag, New York.

Drachman, D. B., and F. Witzke (1972) Trophic regulation of acetylcholine sensitivity of muscle: Effect of electrical stimulation. Science 176: 514-516.

Droz, B., and C. P. Leblond (1963) Axonal migration of proteins in the central nervous system and peripheral nerves as shown by radioautography. J. Comp. Neurol. 121: 325-346.

Dubin, M. W., L. A. Stark, and S. M. Archer (1986) A role for actionpotential activity in the development of neuronal connections in the kitten retinogeniculate pathway. J. Neurosci. 6: 1021-1036.

Durham, D., and E. W Rubel (1985a) Afferent influences on brain stem auditory nuclei of the chicken: Succinate dehydrogenase activity following cochlea removal. J. Comp. Neurol. 231: 446-456.

Durham, D., and E. W Rubel (1985b) Alteration in malate dehydrogenase and laclate dehydrogenase activity in chick brain stem auditory neurons following cochlea removal. Eighth Midwinter Research Meeting, Association for Research in Otolaryngology, Clearwater, FL.

Durham, D., E. W Rubel, and F. M. Matschinsky (1985) Quantitative histochemical measurements of malate dehydrogenase in normal and 
deafferented chick brain stem auditory neurons. Soc. Neurosci. Abstr. 11: 448.

Edwards, D. L., and B. Grafstein (1983) Intraocular tetrodotoxin in goldfish hinders optic nerve regeneration. Brain Res. 269: 1-14.

Edwards, D. L., and B. Grafstein (1986) Intraocular tetrodotoxin reduces axonal transport and transcellular transfer of adenosine and other nucleosides in the visual system of goldfish. Brain Res. 364: 258-267.

Evans, M. H. (1972) Tetrodotoxin, saxitoxin, and related substances: Their application in neurobiology. Int. Rev. Neurobiol. 15: 83-166.

Feng, A. S., and B. A. Rogowski (1980) Effects of monaural and binaural occlusion on the morphology of neurons in the medial superior olivary nucleus of the rat. Brain Res. 189: 530-534.

Fink, R. P., and L. Heimer. (1967) Two methods for selective silver impregnation of degenerating axons and their synaptic endings in the central nervous system. Brain Res. 4: 369-374.

Furber, S., R. W. Oppenheim, and D. Prevette (1987) Naturally-occurring neuron death in the ciliary ganglion of the chick embryo following removal of preganglionic input: Evidence for the role of afferents in ganglion cell survival. J. Neurosci. 7: 1816-1832.

Globus, A. (1975) Brain morphology as a function of presynaptic morphology and activity. In The Developmental Neuropsychology of Sensory Deprivation, A. H. Riesen, ed., pp. 9-91, Academic, New York.

Grafstein, B., D. L. Edwards, and R. M. Alpert (1981) Axonal transport and neuronal activity. In International Cell Biology, H. G. Schweiger, ed., pp. 728-736, Springer-Verlag, New York.

Guillery, R. W. (1974) On structural changes that can be produced experimentally in the mammalian visual pathways. In Essays on the Nervous System, R. Bellairs and E. G. Gray, eds., pp. 299-326, Clarendon Press, Oxford, UK.

Guth, L. (1968) "Trophic" influences of nerve on muscle. Physiol. Rev. 48: 645-687.

Harris, A. J. (1974) Inductive functions of the nervous system. Annu. Rev. Physiol. 36: 251-305.

Harris, A. J. (1980) Trophic effects of nerve on muscle. In The Physiology of Peripheral Nerve Disease, A. J. Sumner, ed., pp. 195-220, Saunders, Philadelphia, PA.

Hille, B. (1968) Pharmacological modifications of the sodium channels of frog nerve. J. Gen. Physiol. 51: 199-219.

Horvitz, H. R., H. M. Ellis, and P. W. Sternberg (1982) Programmed cell death in nematode development. Neurosci. Comment. I: 56-65.

Hyson, R. L., and E. W Rubel (1986) Activity-related uptake of ${ }^{3} \mathrm{H}$ leucine in brain stem auditory and vestibular nuclei of the chicken in vitro. Soc. Neurosci. Abstr. 12: 695.

Kerr, L. M., E. M. Ostapoff, and E. W Rubel (1979) Influence of acoustic experience in the ontogeny of frequency generalization gradients in the chicken. J. Exp. Psychol. [Anim. Behav.] 5: 97-115.

Konigsmark, B. W. (1970) Mehtods for the counting of neurons. In Contemporary Research Methods in Neuroanatomy, W. J. H. Nauta and S. O. E. Ebbesson, eds., pp. 315-340, Springer-Verlag, New York.

Kupperman, B. D., and T. Kasamatsu (1983) Changes in geniculate cell size following brief monocular blockade of retinal activity in kittens. Nature 306: 465-468.

Lavoie, P.-A., B. Collier, and A. Tenenhouse (1977) Role of skeletal muscle activity in the control of muscle acetylcholine sensitivity. Exp. Neurol. 54: 148-171.

Levi-Montalcini, R. (1949) The development of the acoustico-vestibular centers in the chick embryo in the absence of the afferent root fibers and of descending fiber tracts. J. Comp. Neurol. 91: 209-242.

Liberman, M. C. (1978) Auditory-nerve response from cats raised in a low-noise chamber. J. Acoust. Soc. Am. 63: 442-455.

Lippe, W. R., O. Steward, and E. W Rubel (1980) The effect of unilateral basilar papilla removal upon nuclei laminaris and magnocellularis of the chick examined with $\left[{ }^{3} \mathrm{H}\right] 2$-deoxy-D-glucose autoradiography. Brain Res. 196: 43-58.

Lockshin, R. A. (1969) Programmed cell death. Activation of lysis by a mechanism involving the synthesis of protein. J. Insect Physiol. 15. 1505-1516.

Lomo, T., and J. Rosenthal (1972) Control of ACh sensitivity by muscle activity in the rat. J. Physiol. (Lond.) 221: 493-513.

Lomo, T., and R. H. Westgaard (1975) Further studies on the control of ACh sensitivity by muscle activity in the rat. J. Physiol. (Lond.) 252: 603-626.

Maderdrut, J. L., I. Merchenthaler, and R. W. Oppenheim (1984)
Reduction and enhancement of naturally-occurring cell death in the ciliary ganglion of the chick embryo following blockage of ganglionic and neuromuscular transmission. Soc. Neurosci. Abstr. 10: 639.

McArdle, J. J. (1983) Molecular aspects of the trophic influence of nerve on muscle. Prog. Neurobiol. 21: 135-198.

Meyer, R. L. (1983) Tetrodotoxin inhibits the formation of refined retinotopography in goldfish. Dev. Brain Res. 6: 293-298.

Nakamura, Y., S. Nakajima, and H. Grundfest (1965) The action of tetrodotoxin on electrogenic components of squid giant axons. J. Gen. Physiol. 48: 985-996.

Narahashi, T., J. W. Moore, and W. R. Scott (1964) Tetrodotoxin blockage of sodium conductance increase in lobster giant axons. J. Gen. Physiol. 47: 965-974.

Okado, N., and R. W. Oppenheim (1984) Cell death of motorneurons in the chick embryo spinal cord. IX. The loss of motoneurons following removal of afferent inputs. J. Neurosci. 4: 1639-1652.

Parks, T. N. (1979) Afferent influences on the development of the brain stem auditory nuclei of the chicken: Otocyst ablation. J. Comp. Neurol. 183: 655-678.

Parks, T. N. (1981) Morphology of axosomatic endings in avian cochlear nucleus: Nucleus magnocellularis of the chicken. J. Comp. Neurol. 203: 425-440.

Parks, T. N., and E. W Rubel (1978) Organization and development of brain stem auditory nuclei of the chicken: Primary afferent projections. J. Comp. Neurol. 180: 439-448.

Pestronk, A., D. B. Drachman, and J. W. Griffin (1976) Effect of muscle disuse on acetylcholine receptors. Nature 260: 352-353.

Pinching, A. J., and T. P. S. Powell (1971) Ultrastructural features of transneuronal cell degeneration in the olfactory system. J. Cell Sci. 8: 253-287.

Powell, T. P. S., and S. D. Erulkar (1962) Transneuronal cell degeneration in the auditory relay nuclei of the cat. J. Anat. 96: 249-268.

Purves, D., and B. Sakmann (1974) The effect of contractile activity on fibrillation and extrajunctional acetylcholine-sensitivity in rat muscle maintained in organ culture. J. Physiol. (Lond.) 237: 157182.

Ramon y Cajal, S. (1909) The acoustic nerve: Its cochlear branch or cochlea nerve. Histologie du Système Nerveux de l'Homme et des Vertèbres, vol. 1, translated into English (1952), pp. 774-838, Clarendon Press, Oxford, UK (National Technical Information Publication, 1971).

Rebillard, G., and E. W Rubel (1981) Electrophysiological study of the maturation of auditory responses from the inner ear of the chick. Brain Res. 229: 15-23.

Reh, T. A., and M. Constantine-Paton (1985) Eye-specific segregation requires neural activity in three-eyed Rana pipiens. J. Neurosci. 5: 1132-1143.

Rodieck, R. W. (1967) Maintained activity of cat retinal ganglion cells. J. Neurophysiol. 30: 1043-1071.

Rogart, R. (1981) Sodium channels in nerve and muscle membrane. Annu. Rev. Physiol. 43: 711-725.

Rogers, A. W. R. (1979) Techniques of Autoradiography, Elsevier, Amsterdam.

Rubel, E. W, and T. N. Parks (1975) Organization and development of brain stem auditory neurons of the chicken: Tonotopic organization of $\mathrm{n}$. magnocellularis and n. laminaris. J. Comp. Neurol. 164: 411433.

Rubel, E. W, D. E. Born, J. S. Deitch, and D. Durham (1984) Recent advances toward understanding auditory system development. In $R e$ cent Developments in Hearing Science, C. Berlin, ed., pp. 109-157, College-Hill, San Diego, CA.

Sachs, M. B., and J. M. Sinnott (1978) Responses to tones of single cells in nucleus magnocellularis and nucleus angularis of the redwing blackbird (Agelaius phoeniceus). J. Comp. Physiol. 126: 347-361.

Saunders, J. C., R. B. Coles, and G. R. Gates (1973) The development of auditory responses in the cochlea and cochlear nuclei of the chick. Brain Res. 63: 59-74.

Schwartz, J. R., W. Ulbricht, and H. H. Wagner (1973) The rate of action of tetrodotoxin on myclinated nerve fibers of Xenopuslaevis and Rana esculenta. J. Physiol. (Lond.) 233: 167-194.

Seftel, M., J. S. Deitch, and E. W Rubel (1986) Immunocytochemical analysis of cytoskeletal proteins in normal and deafferented nucleus magnocellularis neurons. Ninth Midwinter Research Meeting, Association for Research Otolaryngology, Clearwater, FL.

Silverman, M. S., and B. M. Clopton (1977) Plasticity of binaural 
interaction. I. Effect of early auditory deprivation. J. Neurophysiol. 40: $1266-1274$

Smith, Z. O. J., L. Gray, and E. W Rubel (1983) Afferent influences on brainstem auditory nuclei of the chicken: N. laminaris dendritic length following monaural conductive hearing loss. J. Comp. Neurol. 220: 199-205.

Steward, O., and E. W Rubel (1985) Afferent influences on brain stem auditory nuclei of the chicken: Cessation of amino acid incorporation as an antecedent to age-dependent transneuronal degeneration. J. Comp. Neurol. 231: 385-395.

Stocker, R. F., J. S. Edwards, and J. W. Truman (1978) Fine structure of degenerating abdominal motor neurons after eclosion in the sphingid moth, Manduca sexta. Cell Tissue Res. 191: 317-331.

Streter, F. A., A. R. Luff, and J. Gergely (1975) Effect of cross-reinnervation on physiological parameters and properties of myosin and sarcoplasmic reticulum of fast and slow muscles of the rabbit. J. Gen. Physiol. 66: 811-821.

Stryker, M. P., and W. A. Harris (1986) Binocular impulse blockage prevents the formation of ocular dominance columns in cat visual cortex. J. Neurosci. 6: 2117-2133.

Tower, S. S. (1937) Trophic control of non-nervous tissues by the nervous system: A study of muscle and bone innervated from an isolated and quiescent region of spinal cord. J. Comp. Neurol. 67: 241-267.

Truman, J. W. (1984) Cell death in invertebrate nervous systems. Annu. Rev. Neurosci. 7: 171-188.

Truman, J. W., and L. M. Schwartz (1984) Steroid regulation of neuronal death in the moth nervous system. J. Neurosci. 4: 274-280.

Tucci, D. L., and E. W Rubel (1985) Afferent influences on brain stem auditory nuclei of the chicken: Effects of conductive and sensorineural hearing loss on $\mathrm{n}$. magnocellularis. J. Comp. Neurol. 238: 371-381.

Tucci, D. L., D. E. Born, and E. W Rubel (1987) Changes in spontaneous activity and CNS morphology associated with conductive and sensorineural hearing loss in chickens. Ann. Otol. Rhinol. Laryngol. 96: 343-350.

Warnick, J. E., E. X. Albuquerque, and L. Guth (1977) The demonstration of neurotrophic function by application of colchicine or vinblastine to the peripheral nerve. Exp. Neurol. 57: 622-636.

Webster, D. B. (1983) Auditory neuronal size after unilateral conductive hearing loss. Exp. Neurol. 79: 130-140.

Webster, D. B., and M. Webster (1979) Effects of neonatal conductive hearing loss on brain stem auditory nuclei. Ann. Otol. Rhinol. Laryngol. 88: 684-688.

Wong-Riley, M., and E. W. Carroll (1984) Effect of impulse blockade on cytochrome oxidase activity in monkey visual system. Nature 307 : 262-264.

Wong-Riley, M., and D. A. Riley (1983) The effect of impulse blockade on cytochrome oxidase activity in the cat visual system. Brain Res. 261: 185-193.

Wright, L. (1981) Cell survival in chick embryo ciliary ganglion is reduced by chronic ganglionic blockade. Dev. Brain Res. 1: 283-286.

Young, W. S. III, and M. J. Kuhar (1979) A new method for receptor autoradiography: $\left[{ }^{3} \mathrm{H}\right]$ Opioid receptors in rat brain. Brain Res. 179: 255-270.

Younkin, S. G., R. S. Brett, B. Davey, and L. H. Younkin (1978) Substances moved by axonal transport and released by nerve stimulation have an innervation-like effect. Science 200: 1292-1295. 